\title{
Searching for an Added Value of Precipitation in Downscaled Seasonal Hindcasts over East Africa: COSMO-CLM Forced by MPI-ESM
}

\author{
Bedassa R. Cheneka, ${ }^{1,2}$ Susanne Brienen, ${ }^{1}$ Kristina Fröhlich, ${ }^{1}$ \\ Shakeel Asharaf, ${ }^{1}$ and Barbara Früh ${ }^{1}$ \\ ${ }^{1}$ Deutscher Wetterdienst, Offenbach, Germany \\ ${ }^{2}$ Agriculture Transformation Agency, P.O. Box 708, Addis Ababa, Ethiopia \\ Correspondence should be addressed to Bedassa R. Cheneka; beregassa@gmail.com
}

Received 11 November 2015; Accepted 17 February 2016

Academic Editor: Hann-Ming H. Juang

Copyright ( 2016 Bedassa R. Cheneka et al. This is an open access article distributed under the Creative Commons Attribution License, which permits unrestricted use, distribution, and reproduction in any medium, provided the original work is properly cited.

\begin{abstract}
Downscaling of seasonal hindcasts over East Africa with the regional climate model (RCM) COSMO-CLM (CCLM), forced by the global climate model (GCM) and MPI-ESM, is evaluated. The simulations are done for five months (May to September) for a ten-year period (2000-2009), with the evaluation performed only for June to September. The dry years, 2002 and 2009, and the wet years, 2006 and 2007, are well captured by the models. By using ground based and satellite gridded observation data for evaluation it is found that both COSMO-CLM and MPI-ESM overestimate June to September precipitation over the Ethiopian highlands and in parts of the lowland with respect to all reference datasets. In addition we investigated the potential and real added value for both the RCM and the GCM hindcasts by upscaling (arithmetic mean) the precipitation resolution both in temporal and in spatial scales, over North Ethiopia (EN), South Ethiopia (ES), South Sudan (SS), and Sudan (S). Results inferred that using the RCM for seasonal forecast adds value in capturing extreme precipitation years, especially in the Ethiopian highlands. It is also found that the potential and relative potential added value decrease with decreasing the temporal resolution.
\end{abstract}

\section{Introduction}

Truthful and reliable seasonal rainfall prediction is important for social and economic value for the East African countries, which are susceptible to floods and droughts recurrently for many years. The recent flood years 2006 and 2007 [1] (http://www.pecad.fas.usda.gov/) and in 2010-2011 (http://reliefweb.int/) and 1984, 2002, and 2009 are drought years [2] over East Africa which are the typical examples. In this region, the economy is highly dependent on rainfed agriculture and pastoral economy. The main rainfall season varies from region to region in Ethiopia. For instance, southern Ethiopia depends strongly on spring (FebruaryMay) precipitation, whereas June to September (JJAS) is the main rainy season in central and northern Ethiopia. Regionally, JJAS contributes to more than $70 \%$ of the annual precipitation in the central, north, and northwest Ethiopia;
October-November is the second rainy season in the south and southeast, providing $20-26 \%$ of the total annual precipitation. During December to January, all parts of the country receive less than $6 \%$ of the total annual precipitation [2].

Ethiopia is an East African country. Its agricultural and food grain production depend strongly on JJAS precipitation to secure adequate food supply. For instance, June to September rainfall contributes $85-90 \%$ to crop production in Ethiopia [3]. Understanding seasonal fluctuations of precipitation in distribution, amount, onset, and cessation has an important contribution for the crop calendar of the country. Segele and Lamb [4] found that rainfall onset and cessation over Ethiopia are influenced by the strength of the Tropical Easterly Jet (TEJ), the ENSO phase (El Niño Southern Oscillation), and sea surface temperatures (SST) in the Indian Ocean and the Arabian Sea. 
The demand of reliable climate information is increasing in the last decades for agriculture crop yield production [5], health impacts $[6,7]$, and water resources [8]. The impact assessment tool, "Livelihoods, Early Assessment and Protection" (LEAP) (http://www.agriskmanagementforum.org/), was built in 2008 by the Ethiopian Drought Insurance project (EDI). The Ethiopian government, the World Food Program (WFP), and the World Bank established LEAP as an integrated food security early warning response. This research is a preparation study to evaluate the regional seasonal forecasts of the past (hindcasts) in order to implement the regional seasonal forecast into the LEAP, early warning, and food security prototype.

Predictability of seasonal rainfall depends on the ability of the prediction systems to quantify the depth and the flow of moisture, regional and global systems, and the atmospheric dynamics that initiate seasonal precipitation [9]. Large-scale teleconnections, such as ENSO, and the Indian Ocean Dipole affect East African rainfall by influencing the position of ITCZ and strength of the regional convective systems $[10,11]$. The wet phase of ENSO is associated with a deficiency of JJAS rainfall over the Ethiopian highlands. Another contributor is the Tropical Easterly Jet (TEJ), which is the most important upper level feature for the summer rainfall in Ethiopia. A stronger (weaker) TEJ is generally associated with longer (shorter) wet spells [4]. Circulation at lower levels also plays a significant role on seasonal rainfall amount and distribution, where moisture flux from the Indian and Atlantic Oceans and the intensities and positions of the Mascarene and St. Helena high pressure systems affect East Africa precipitation [12]. Previous studies on seasonal rainfall forecast of East Africa have found that June to September precipitation is governed by tropical western Indian Ocean sea surface temperature (SST), Niño 3.4 region [13], ENSO Phases [14], and SST of Indian, Atlantic, and Pacific Ocean [15].

Due to the development in high-performance computing and data availability on both spatial and temporal scales, major studies have been carried out through the use of a global climate model (GCM). However, GCMs often fail in capturing regional fine scale features and processes because of their coarse grid spacing, which is approximately $200 \mathrm{~km}$. This problem can be solved to some extent by downscaling, either statistically or dynamically, the GCM outputs. Statistical downscaling is computationally simple and efficient; however it needs long historical data and also depends on the relation of predictor and predictand. The dynamical downscaling technique uses a regional climate model (RCM) that has been applied for operational climate prediction and/or weather forecast to provide climate information for socioeconomic development on a regional scale in most parts of the world. RCMs have been widely used in simulating the climate over midlatitude regions; however a few studies considered the climate of the African region [16-21]. Those studies revealed that the regional climate models capture intraseasonal variations of precipitation over Africa; the rainfall intensity is strongly determined by the applied convection scheme, the structure of the development of storm circulation is well simulated, and an increase of vertical resolution improves the precipitation and wind field simulation. In a recent dynamical seasonal hindcast study over East Africa, Diro et al. [22] found that the regional climate model reproduces both spatial and interannual variability of seasonal rainfall and captures the teleconnection between ENSO and regional precipitation structure. However, it has to be taken into account that the dynamical seasonal downscaling depends on the quality of the GCM data which are used for initial and lateral boundary conditions.

Simulations of precipitation by regional climate models generally add values by incorporating local processes and internal model physics [23]. The regional climate model COSMO-CLM (or CCLM), which is used in this study, is generally able to reproduce the broad and basic features of the African climate [24]. For example, COSMO-CLM is able to capture the seasonal temperature comparable to other RCMs $[25,26]$ with a bias generally ranging between + and $-2^{\circ} \mathrm{C}$ over Africa.

The aim of this paper is to investigate the potential of COSMO-CLM to predict rainfall over East Africa forced by the global climate model MPI-ESM in a seasonal hindcast setup. Precipitation and its spatial and temporal bias with respect to observed and satellite gridded precipitation data is the main focus of this study.

Another subject of this paper is the evaluation of the added value of COSMO-CLM seasonal hindcast precipitation over East Africa. The potential advantage of a RCM is to improve the simulation of small scale climate processes that are not well described by a low-resolution global circulation model [27]. A broader range of fine spatial scales is explicitly resolved by improving the representation of surface forcing such as mountains, water bodies, and coastal regions.

Therefore, an added value (AV) can be attributed to RCM simulations in climate variability at scales that are not explicitly resolved by GCMs (AV1) and should further improve the simulation of climate in those scales that are common to both RCMs and GCMs (AV2) [27].

Added value is categorized as "real added value" when used with respect to observed data and "potential added value" by aggregating the model output onto a coarse grid virtual regional climate model. Since the current paper focuses on precipitation only, the potential added value is defined as the difference between high resolution precipitation and coarse resolution aggregated precipitation.

In summary, the aims of this study are (i) to evaluate the potential of both the COSMO-CLM and the MPI-ESM model in performing seasonal hindcasts of the JJAS cycle and their interannual variability of precipitation over East Africa, (ii) to evaluate the spatial bias of COSMO-CLM and MPI-ESM over East African lowlands and Ethiopian mountainous regions, (iii) to investigate the precipitation frequency distribution over multiple scales as well as extreme precipitation, and (iv) to evaluate real and potential added value of precipitation over East Africa using the methods of Di Luca et al. [27, 28].

This paper is organized as follows. Section 2 describes the data and methods. In Section 3 the performance of COSMOCLM seasonal hindcasts is described; Section 4 discusses the added value and extreme precipitation indices. Finally in Section 5 we conclude and summarize the results. 


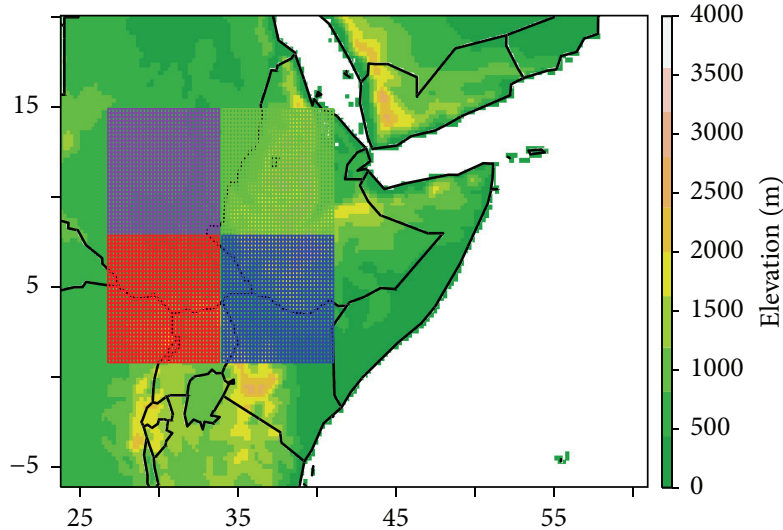

(a)

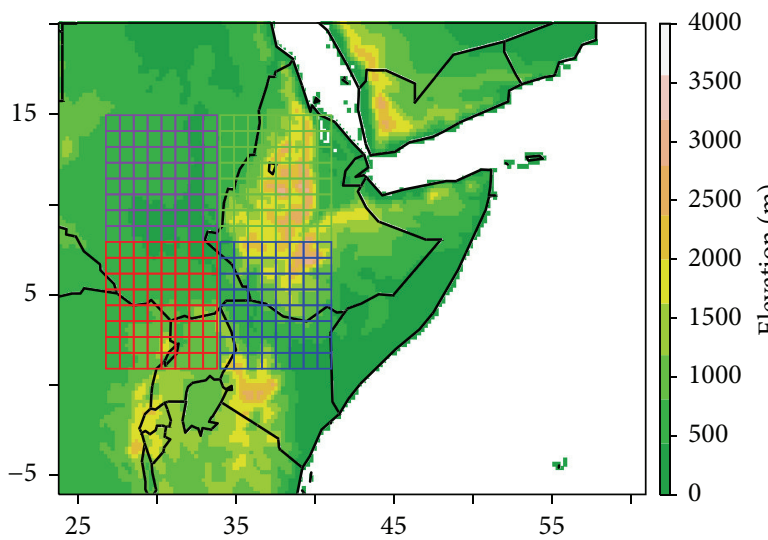

(c)

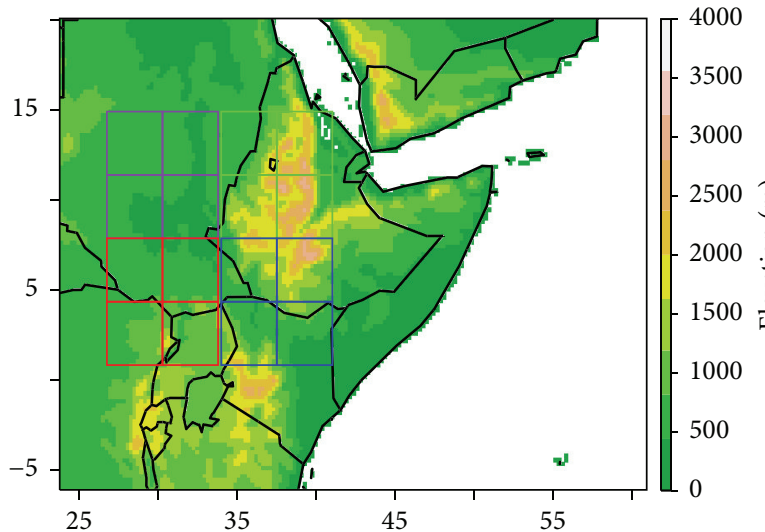

(e)

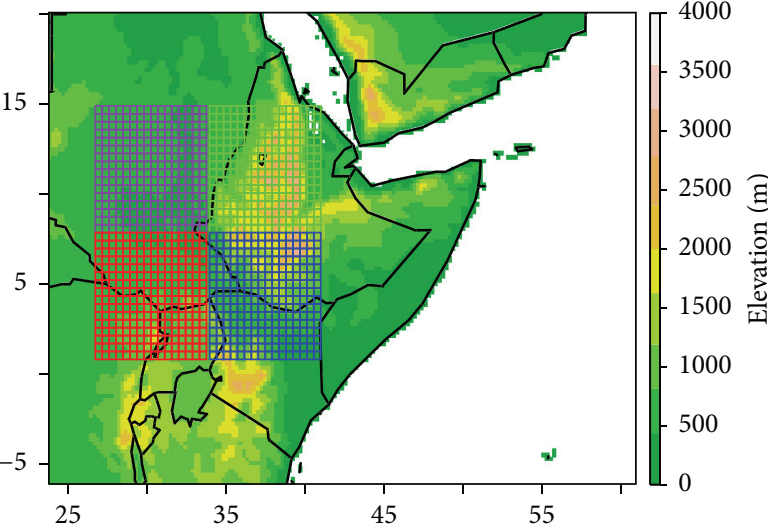

(b)

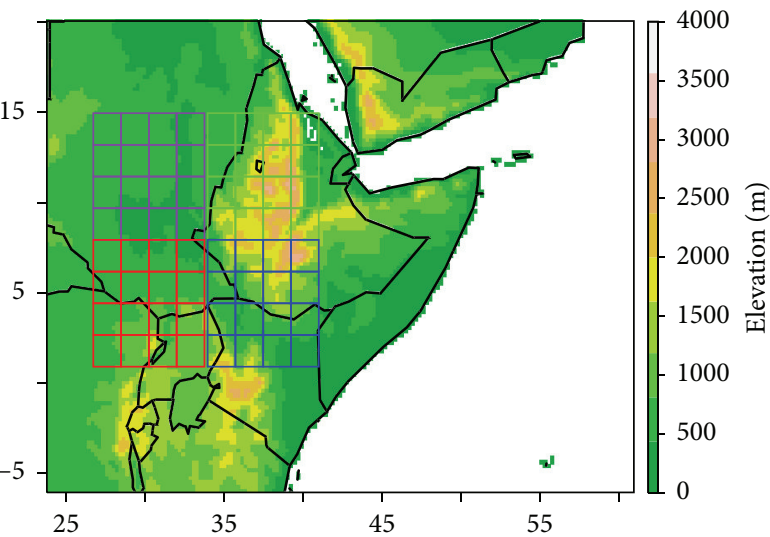

(d)

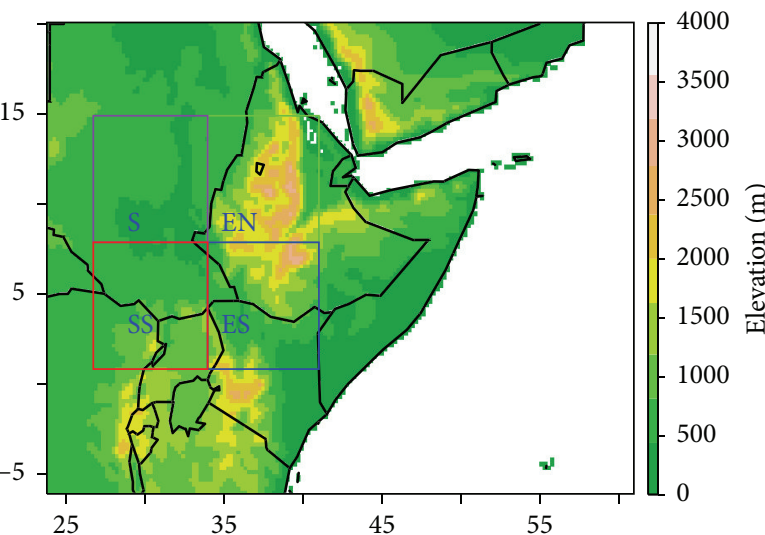

(f)

FIgURE 1: Simulation domain over East Africa, where the colour scale shows the elevation (m) over the entire region. The boxes represent the four investigated subregions: North Ethiopia (EN: green), South Ethiopia (ES: blue), South Sudan (SS: red), and Sudan (S: purple). The different panels show the representation of the grid in each region for the calculation of potential and relative potential added value: (a) original $0.22^{\circ}$, (b) $0.44^{\circ}$, (c) $0.88^{\circ}$, (d) $1.76^{\circ}$, (e) $3.72^{\circ}$, and (f) $7.04^{\circ}$.

\section{Description of the Region}

Spatial precipitation is analysed over East Africa, a region which is highly variable in precipitation amount and distribution, orography, and ecological aspects. Temporal precipitation is therefore analysed in detail for the subregions: North
Ethiopia (EN), South Ethiopia (ES), Sudan (S), and South Sudan (SS) (Figure 1 and Table 1).

Each region with the exception of ES experiences rainfall more than $2 \mathrm{~mm} / \mathrm{d}$ during the June to September months as the different observational data show in Figure 2. Orographic height and land surface characteristics of each region are 

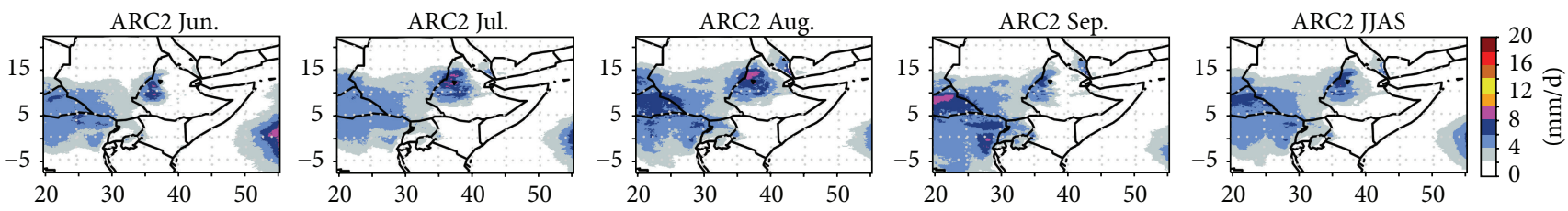

(a)
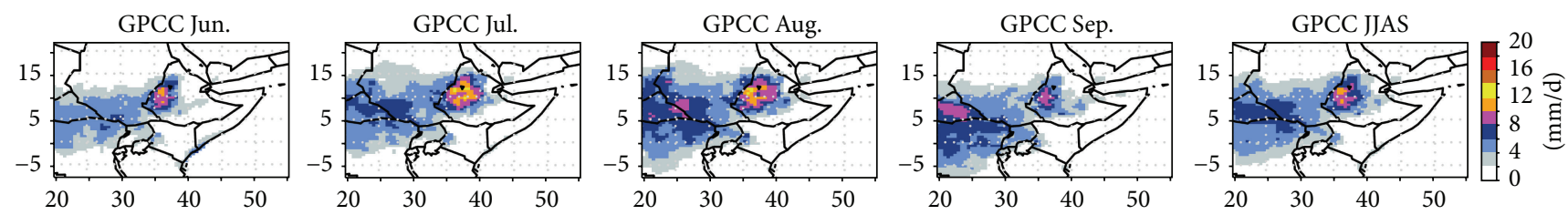

(b)
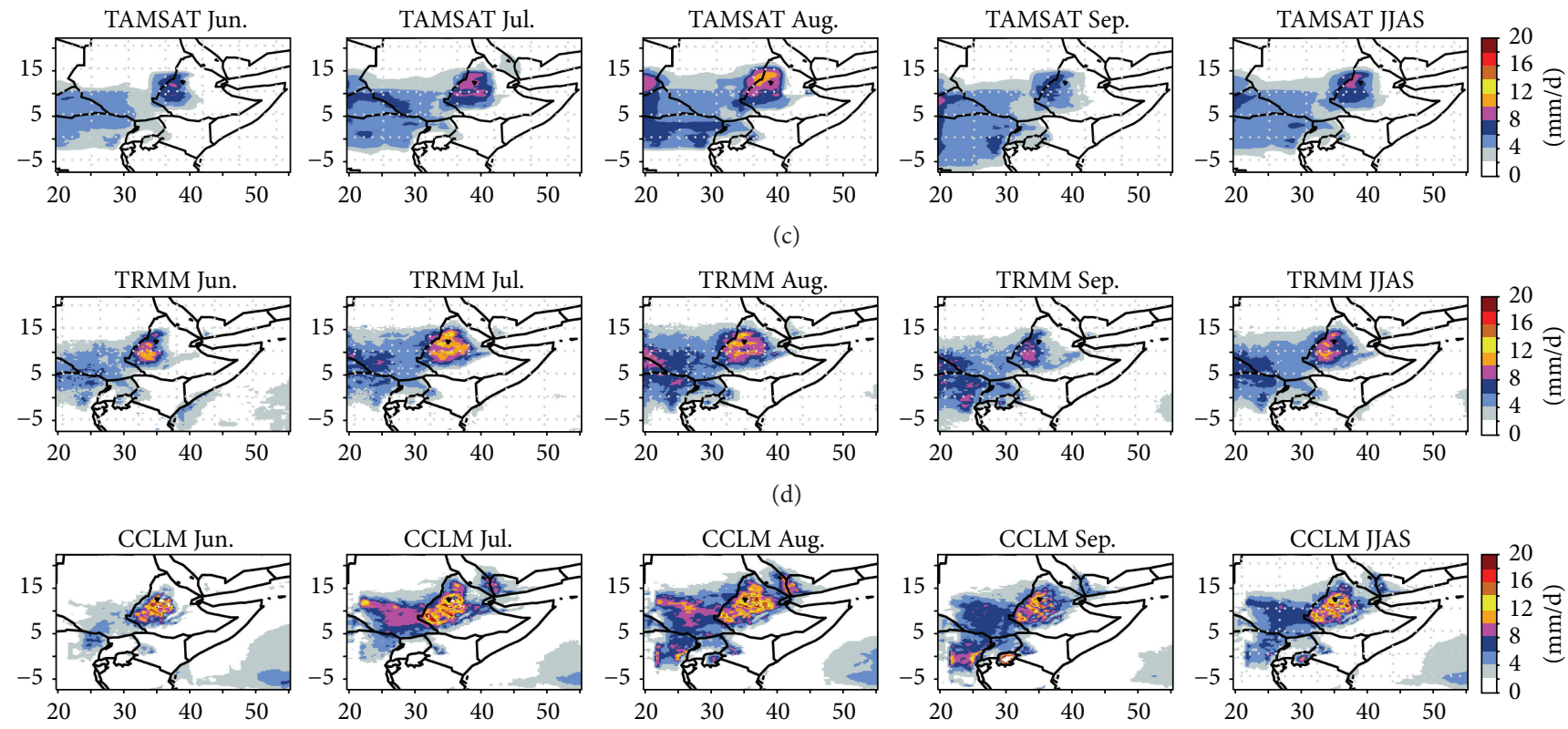

(e)
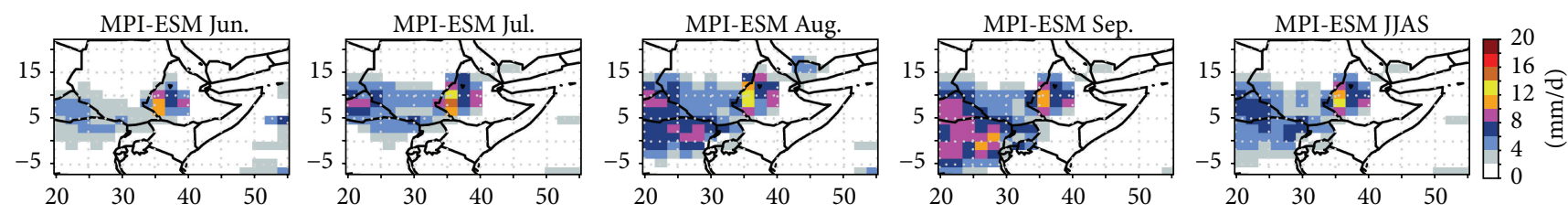

(f)

FIGURE 2: Spatial distribution of mean daily precipitation (mm/d) for ARC2 (first row), GPCC (second row), TAMSAT (third row), TRMM (fourth row), COSMO-CLM (fifth row), and MPI-ESM (last row). Each column represents, respectively, June, July, August, September, and JJAS mean precipitation of 2000-2009.

quite different. A brief description of the used subregions is given below.

North Ethiopia (EN). It is a region where highly distinct mountainous terrain exists with the highest mountain (and the tenth highest in Africa) being found with summits reaching up to $4,550 \mathrm{~m}$ height. This region receives an immense amount of tropical convective rainfall [29].

South Ethiopia (ES). The southern part of Ethiopia is covered by dense forests and lakes such as Abaya and Chamo and
Turikana. In this region the Omo National Park, Nechisar National Park, and Sibiloi National Park are located. The hydrological cycle of this region is very stable and experiences two rainy seasons, March-April-May (MAM) and SeptemberOctober-November (SON) [30].

South Sudan (SS). In contrast to the above-mentioned regions SS is described by savannas, a huge swamp region and jungle in the southern part. As described in [30] this region receives maximum rainfall from April to October and stays dry in the remaining months. The main sources for moisture 
TABLE 1: Geographical coordinates of the selected regions (cf. Figure 1).

\begin{tabular}{lcc}
\hline Name & Lon $\left({ }^{\circ} \mathrm{E}\right)$ & Region \\
\hline EN & $34.00-41.05$ & lat $\left({ }^{\circ} \mathrm{N}\right)$ \\
ES & $34.00-41.05$ & $7.887-14.9$ \\
S & $26.76-34.00$ & $0.83-7.87$ \\
SS & $26.76-34.00$ & $7.87-14.9$ \\
\hline
\end{tabular}

are the south-westerly monsoon winds from the Atlantic Ocean and south-easterly monsoon from the Indian Ocean. The intertropical convergence zone (ITCZ) migration also governs the temporal and spatial variability of rainfall.

Sudan (S). This lowland region is mostly characterized by bare land. The latter two regions are highly vulnerable with respect to negative rainfall anomalies during a season.

\section{Model Setup and Data}

The initial and boundary conditions of COSMO-CLM were taken from the Earth System Model MPI-ESM [31]. It is worth mentioning here that these results were available in the process of preparation for a seasonal forecasting system. MPIESM couples the atmosphere, ocean, sea-ice, and land and was used in a CMIP5-close configuration. The configuration and evaluation of the seasonal forecast system is described in [32]. It has to be taken into account that the model resolution, both in atmosphere and in ocean, is quite coarse with T63 ( $240 \mathrm{~km}$ grid distance) in the atmosphere and $1.5^{\circ}$ grid distance in the tropical ocean.

The COSMO-CLM model is a nonhydrostatic limitedarea weather/climate model based on the thermohydrodynamical equations, describing compressible flow in a moist atmosphere [33, 34]. The model is formulated on rotated geographical coordinates with a generalized terrain following height coordinate system. Convection is parameterized by a Tiedtke convection scheme [35]. In the present study, COSMO-CLM was set to a $0.22^{\circ}$ horizontal resolution, covering the East African regions as shown in Figure 1.

We chose to study the first ten years of the second millennium, since strong anomalies occurred in this decade. In 2006 and 2007 East Africa experienced floods and in 2009 a drought occurred. Further, this period is documented very well by different observational, ground based, and satellite datasets as well as reanalyses such as TAMSAT, TRMM, ARC2, and GPCC, which could provide an improved platform to assess the current results. Therefore, the hindcast simulations with COSMO-CLM are performed for the ten years 2000 to 2009, from May to September, where May is used as spin-up period and therefore discarded from the current analysis. This period also overlaps with periods chosen by the EUPORIAS (European Provision of Regional Impact Assessment on a Seasonal to Decadal Timescale) project, which is a strategic approach to provide an improved skill in seasonal prediction over East African region.
As mentioned above, a number of surface gridded observations and ground based and satellite data are used to evaluate the seasonal hindcasts of East Africa precipitation. One is a newly reconstructed Africa Rainfall Climatology (ARC2) [36], combining the recent recalibrated infrared (IR) imagery European Meteorological Satellite (EUMETSAT) and daily rain gauge data. It provides nearly real time data of daily rainfall estimation at $0.1^{\circ}$ horizontal resolution and is used for the Africa Famine Early Warning System (AFEWS) impact assessment tool. An available satellite rainfall product is TAMSAT (Tropical Applications of Meteorology using Satellite Data), which is based on IR observations at $0.0375^{\circ}$ horizontal resolution over Africa [37]. Over Africa TAMSAT is used as input for early warning assessment tools and food security applications. Data from another satellite, the Tropical Rainfall Measuring Mission (TRMM) Multisatellite Precipitation Analysis 3B42 version 7 [38], combine observations from rain gauges, geostationary infrared (IR), and low-earth orbiting passive microwave (MW), based on cloud top brightness temperature at cold cloud tops. Rainfall estimates are scaled to monthly rainfall provided by the Global Precipitation Climatological Center (GPCC) [39]. TRMM is available at 0.25 spatial horizontal resolution and at daily temporal resolution from 1998 to 2010.

By comparing TAMSAT and ARC2 against rain gauges over Ethiopia it has been found that both underestimate the rainfall amount. However, TAMSAT shows good skill in detecting rainy events while ARC2 underestimates the frequency of rainy events [30]. Meanwhile, Tropical Rainfall Measuring Mission (TRMM) consistently performs best in detecting rainy events and capturing the mean rainfall and seasonal variability [30]. A Global Precipitation Climatology Center (GPCC) product based on gauged monthly precipitation data for the global land surface available at $0.5^{\circ}$ horizontal resolution [40] is also used in this study for the model evaluation.

\section{Methods}

We standardize the precipitation products by taking out the climatological mean and divide the anomalies by standard deviation to investigate climatological rainfall anomalies. Hart and Grumm [41] used normalized departures from climatology to objectively rank synoptic-scale events. Root mean square error (RMSE) and mean difference (bias) are also measured for nonstandardized precipitation amount to evaluate the simulated precipitation error with reference to the gridded precipitation datasets.

To evaluate the added value of regional climate model we use real and potential added value metrics as suggested by Di Luca et al. [27, 28]. Real added value uses observed datasets to evaluate the regional climate model output. On the other hand, the maximum achievable added value of a RCM is called the potential added value. Following Di Luca et al. $[27,28]$, real added value (AV) and potential added value (PAV) are calculated.

For the calculation of the spatial real added value (rAV), we use the formulation from the recently published paper on 
CORDEX Africa [42] which was adapted from Di Luca et al. [28]:

$$
\mathrm{rAV}=\frac{\left(X_{\mathrm{GCM}}-X_{\mathrm{Obs}}\right)^{2}-\left(X_{\mathrm{RCM}}-X_{\mathrm{Obs}}\right)^{2}}{\operatorname{Max}\left(\left(X_{\mathrm{GCM}}-X_{\mathrm{Obs}}\right)^{2},\left(X_{\mathrm{RCM}}-X_{\mathrm{Obs}}\right)^{2}\right)} .
$$

rAV is positive if the squared error of the RCM is less than GCM's squared error. $X$ in this paper is the temporal mean precipitation. The normalization is introduced such that $-1 \leq$ $\mathrm{rAV} \leq 1$. If $\mathrm{rAV}>0$ the RCM has added value whereas $\mathrm{rAV}<$ 0 RCM has no added value.

Potential and relative potential added values for extreme precipitation values, 90th and 95th percentiles, are evaluated for COSMO-CLM and ARC2 due to availability of data on a daily temporal scale. For the calculation of potential added value, the high resolution regional climate model output is aggregated into a coarse resolution regional climate model scale, called virtual GCM (vGCM), following Di Luca et al. [27]. The multiscale resolution approach is applied in order to find the scale dependence of precipitation on spatial and temporal resolution $[27,43]$.

The difference between the high resolution RCM and the coarse resolution vGCM climatic statistics can be highlighted as PAV measure:

$$
\mathrm{PAV}^{n, m}=X_{\mathrm{RCM}}^{n, m}-X_{\mathrm{vGCM}}^{n, m},
$$

where $X$ is the 90th or 95th percentile value of precipitation. The superscripts $n$ and $m$ indicate the temporal and spatial scale, respectively. As stated above, $X_{\mathrm{RCM}}$ refers to the high resolution RCM at $0.22^{\circ}$ and $X_{\mathrm{VGCM}}$ is the aggregated value at low horizontal resolution of $3.54^{\circ}$. The relative potential added value (rPAV) is the ratio of potential added value (PAV) to the high resolution precipitation value [27]:

$$
\mathrm{rPAV}^{n, m}=\frac{\mathrm{PAV}^{n, m}}{X_{\mathrm{RCM}}^{n, m}}=1-\frac{X_{\mathrm{vGCM}}^{n, m}}{X_{\mathrm{RCM}}^{n, m}} .
$$

rPAV is varying from 0 to 1 . An rPAV close to zero indicates that no fine scale information is added by the RCM to the vGCM, whereas for $\mathrm{rPAV} \sim 1$ the climatic statistic $X$ is determined by fine scale information.

We perform spatial filtering by aggregating COSMOCLM and ARC2 daily precipitation from the original resolution $\left(0.22^{\circ}\right)$ into multiple low resolutions $\left(0.44^{\circ}, 0.88^{\circ}, 1.66^{\circ}\right.$, $3.52^{\circ}$, and $7.04^{\circ}$ ) step by step by computing an arithmetic spatial mean over each grid box separately for the four regions.

The temporal filtering is also done by aggregating daily precipitation into low temporal resolution (2 days, 4 days, 8 days, and 16 days). We discuss daily and 16-day potential added value and 90th and 95th percentiles aggregated precipitation with respect to multiscale horizontal resolution. The 16-day spatial aggregation is used to deduct how strong the small scale features provide information at low temporal scale.

\section{Results and Discussions}

5.1. Performance of COSMO-CLM Seasonal Hindcast Simulations. In this section, we discuss the performance of the seasonal hindcast simulations with COSMO-CLM over East Africa. The spatial distribution and the bias of COSMO-CLM and MPI-ESM precipitation are investigated. The variation of June to September daily precipitation and its standardized interannual variability are analysed over the selected regions with respect to ARC2, GPCC, COSMO-CLM, and MPI-ESM. For the same regions, temporal RMSE and mean difference (bias) are calculated.

5.2. Spatial Structure of Precipitation. Figure 2 displays the 10-year mean of each month and the 4-month mean for all datasets investigated in this study. Daily mean rates are used here to stay consistent in terms of unit with the following investigated metrics. As a general feature it can be seen that precipitation increases in amount and distribution over the course of the rainy season and reaches peak values in August. During JJAS, northern mountainous (highland) Ethiopia benefits mostly from the rainfall, whereas South West and South East Ethiopia receive less rain during the season. There are, however, some discrepancies in the spatial distribution of precipitation among the observed gridded datasets. The GPCC shows the strongest values compared to $\mathrm{ARC} 2$, because the number of gauged stations used is maximum compared with ARC2, while the climatology ARC2 displays very low precipitation amount due to unavailability of daily Global Telecommunication System (GTS) report in real time and deficiencies in satellite estimate over coastal and orographic areas $[30,39]$. The satellite TAMSAT is stronger than ARC2 in capturing peak rainfall amount over the highlands of Ethiopia, because its rainfall estimated calibration is done with a large database of historical rain gauge observations, and the calibration varies monthly and seasonally to account for local and seasonal variations between cloud top temperature and rainfall [30]. The TRMM 3B42 shows similar values as GPCC in amount and distribution over East Africa. The precipitation amount $(>8 \mathrm{~mm} / \mathrm{d})$ of the JJAS average over the Ethiopian highlands appears in all precipitation products, except in the ARC2. This has been already found by Young et al. [30]. TAMSAT precipitation amount is similar to ARC2 which shows low precipitation over Ethiopian highland in June and September compared to TRMM, GPCC, and global and regional model precipitation output. We observe similar behaviour in precipitation amount between TRMM, GPCC, TAMSAT, COSMO-CLM, and MPI-ESM over Ethiopian highland in June, July, August, September, and JJAS. However, in September TAMSAT shows low values of precipitation. TRMM, GPCC, and TAMSAT precipitation distribution is consistent over South Sudan. Again, the high precipitation values in August and September are not captured by TAMSAT and ARC2 but are observed in the other observation datasets. TRMM 3B42 and GPCC agree in amount and distribution over East Africa, especially over Ethiopian highlands, Northern Tanzania, and South Sudan.

In contrast to the observed data COSMO-CLM and MPIESM simulated rainfall amounts behave differently. First, both models already show high values in June, July, August, and September over highland of Ethiopia. Second, in August 

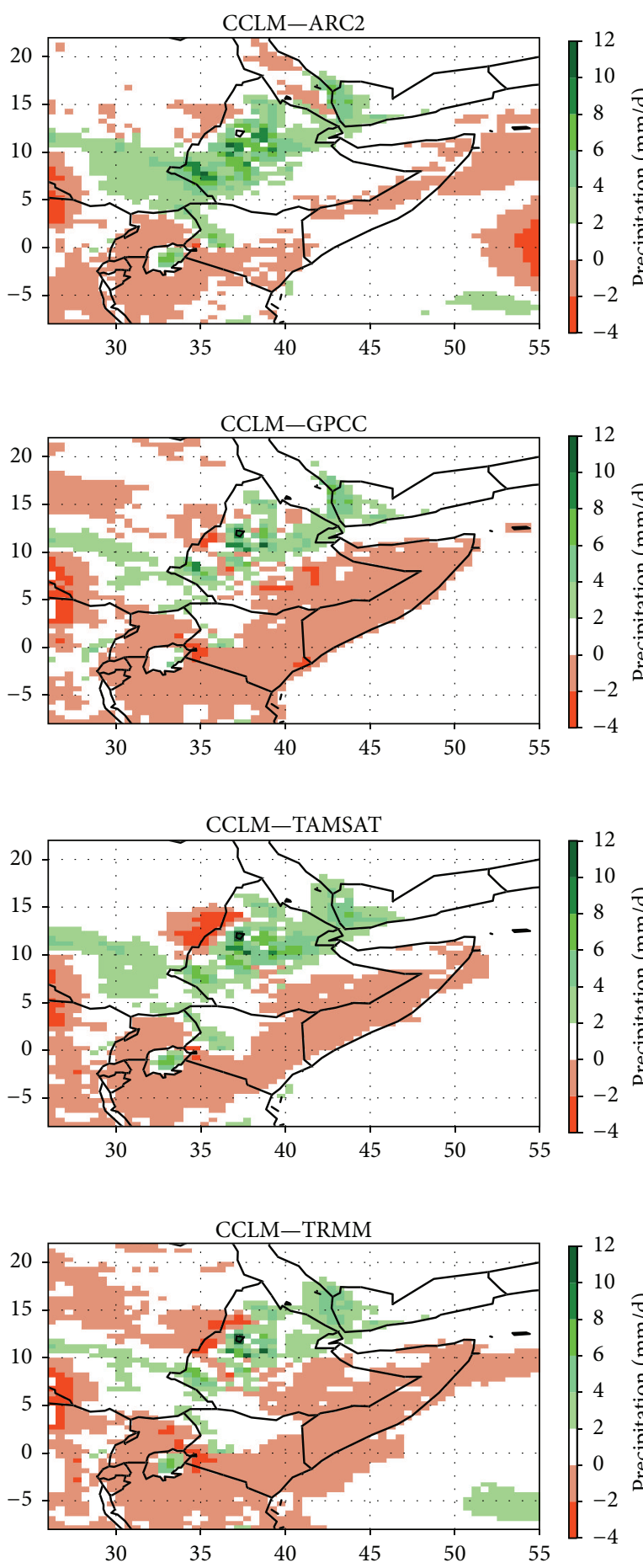

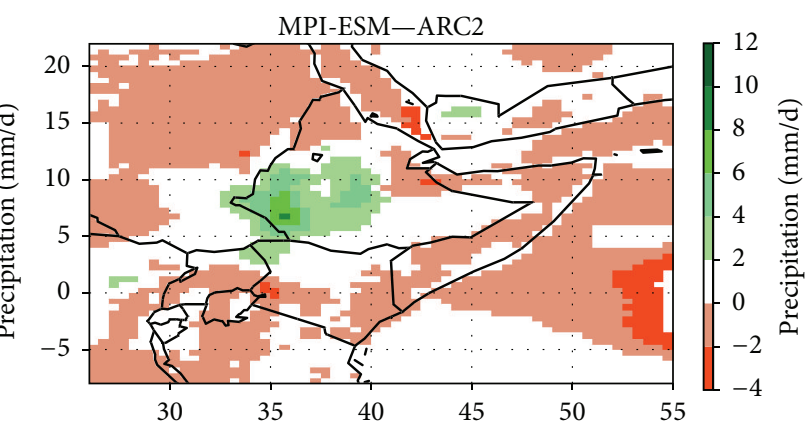

(a)

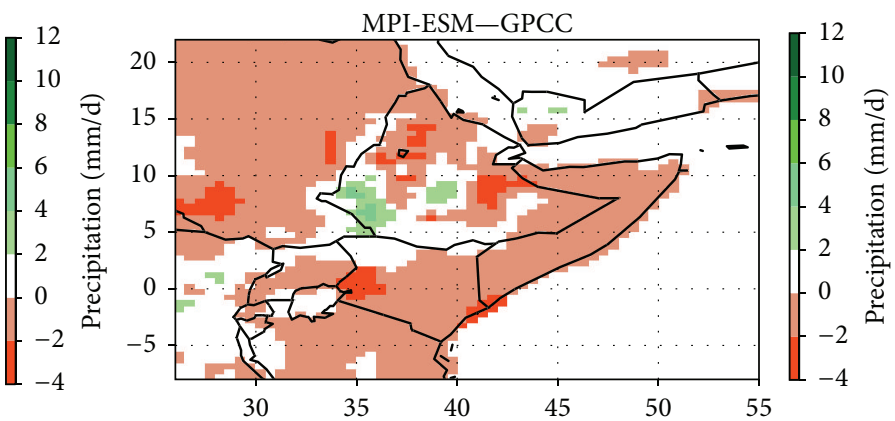

(b)

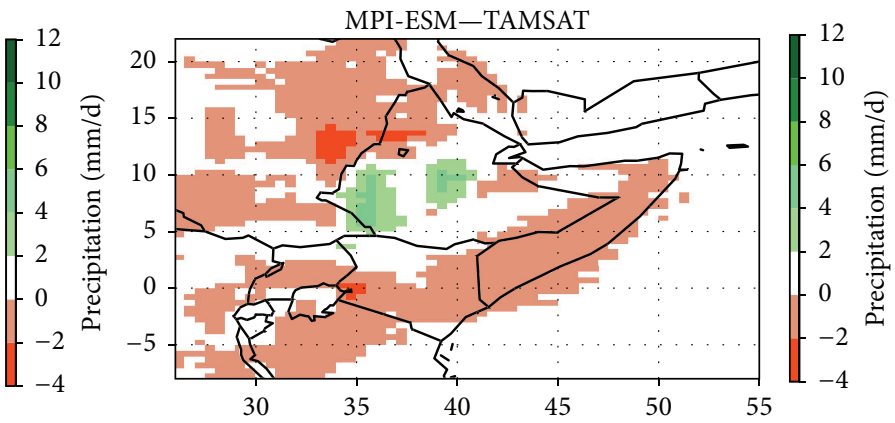

(c)

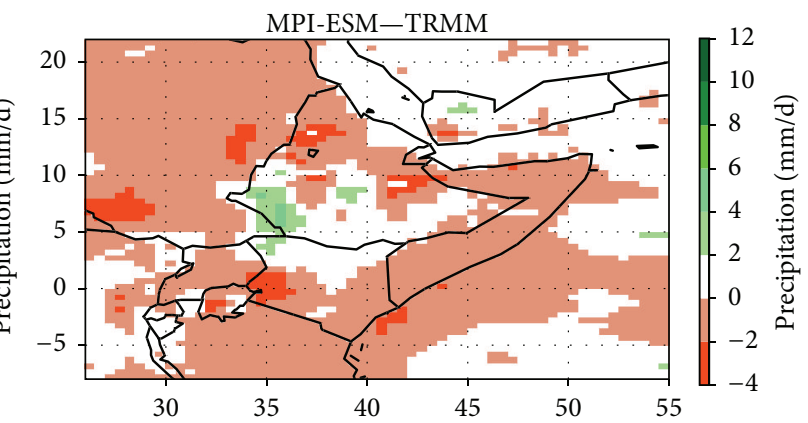

(d)

FIGURE 3: Spatial bias of JJAS average daily precipitation for COSMO-CLM (first row) and MPI-ESM (second row) from top to down with respect to ARC2, GPCC, TAMSAT, and TRMM.

and September not only the values but also the distribution differs as the models show very high precipitation amounts over South Sudan with MPI-ESM precipitating further south than COSMO-CLM. In summary, global and regional model results are compared to a selected dataset for the average over the whole seasonal hindcast period of JJAS and found that
COSMO-CLM does capture the heavy precipitation events reasonably well over the Ethiopian highlands.

COSMO-CLM exhibits a wet bias with respect to all reference precipitation datasets over the Ethiopian highlands, South Sudan, and western parts of Yemen (Figure 3). MPI-ESM also has the wet bias over Southwestern and 
Northeastern parts of Ethiopia and low wet bias over central Ethiopia with respect to all reference datasets. However, magnitude and spatial extension of the MPI-ESM wet bias over the Ethiopian mountainous region are smaller compared to COSMO-CLM. Over most parts of Somalia, Kenya, Tanzania, and Uganda both COSMO-CLM and MPI-ESM show a slight dry bias. Over Northern Sudan, a dry bias in MPI-ESM is in contrast to no or a slight wet bias in COSMO-CLM. The most remarkable differences between the models occur over South Sudan and Rwanda, with a dry bias in the global and a wet bias in the regional model. TRMM and GPCC have similar rainfall amount and distribution; therefore the spatial bias value and its distribution are comparable for COSMO-CLM and MPI-ESM in most parts of the region (Figures 2 and 3). In general, COSMO-CLM and MPI-ESM show a predominant wet bias for the region where JJAS is the main rainy season, for instance, Ethiopia. However, for regions where MAM is the main rainy season, COSMO-CLM and MPI-ESM show mainly a dry bias, for example, Kenya.

In Table 2 the root mean square error and mean difference (bias) are calculated over the four selected regions (region information is given in Table 1). COSMO-CLM and MPIESM precipitation data are evaluated with respect to the reference datasets ARC2, TAMSAT, TRMM, and GPCC. It can be seen that COSMO-CLM has a wet (positive) bias with respect to all reference datasets over all the regions and a higher RMSE compared to the MPI-ESM. The highest RMSE value for COSMO-CLM is found compared to all observations over the EN region, with $5.6(\mathrm{~mm} / \mathrm{d})$ with respect to TAMSAT and with $1.63(\mathrm{~mm} / \mathrm{d})$ with respect to TRMM. For MPI-ESM, the situation is different with only TAMSAT showing the highest RMSE value over the EN region, whereas values are highest with respect to ARC2 over ES and with respect to GPCC and TRMM over the S region.

Generally, the precipitation of COSMO-CLM shows a higher statistical bias and root mean square error compared with the bias and root mean square error of MPI-ESM over most of the selected regions. Similar results were obtained by Dosio et al. [42] who performed and analysed CMIP5 scenarios over CORDEX Africa among them CCLM driven by MPI-ESM. Their comparison of downscaled precipitation showed that CCLM has a higher bias and RMSE than MPI-ESM-LR. It is speculated that CCLM double counts precipitation generated by the convection scheme and on the grid scale. Mariotti et al. and Laprise et al. [23, 44] also showed that RCM physics (soil parameterization, convection schemes, etc.) play a significant role in reproducing the regional precipitation distribution over Africa.

5.3. Temporal Precipitation Structures. The seasonal precipitation cycles are analysed as a domain average over the four selected regions. The gridded datasets ARC2, TAMSAT, TRMM, and GPCC as well as the global and the regional model are compared for each region as shown by monthly climatology in Figure 4 . The ARC2 values are clearly the lowest, especially over the EN and ES region, again confirming the results of Young et al. [30]. Taking GPCC as reference, COSMO-CLM overestimates daily mean
TABLE 2: RMSE and mean difference (bias) of JJAS daily precipitation $(\mathrm{mm} / \mathrm{d})$ averaged over the four regions for COSMO-CLM (CCLM, (a)) and MPI-ESM (b).

(a)

\begin{tabular}{lccc}
\hline & Region & RMSE & Bias \\
\hline \multirow{4}{*}{ CCLM versus GPCC } & EN & 1.91 & 1.83 \\
& ES & 0.97 & 0.61 \\
& S & 1.23 & 0.94 \\
& SS & 0.78 & 0.29 \\
\hline \multirow{2}{*}{ CCLM versus ARC2 } & EN & 3.65 & 3.59 \\
& ES & 2.06 & 1.98 \\
& S & 1.89 & 1.64 \\
CCLM versus TAMSAT & SS & 1.33 & 1.18 \\
\hline & EN & 5.6 & 5.62 \\
& ES & 1.39 & 1.22 \\
& S & 3.42 & 3.32 \\
CCLM versus TRMM & SS & 2.30 & 2.26 \\
\hline & EN & 1.63 & 1.53 \\
& ES & 1.23 & 0.98 \\
& S & 1.07 & 0.73 \\
& SS & 0.80 & 0.05 \\
\hline
\end{tabular}

(b)

\begin{tabular}{lccc}
\hline & Region & RMSE & Bias \\
\hline \multirow{3}{*}{ MPI-ESM versus GPCC } & EN & 0.57 & -0.07 \\
& ES & 0.897 & 0.70 \\
& S & 0.91 & -0.86 \\
& SS & 0.75 & -0.37 \\
\hline \multirow{2}{*}{ MPI-ESM versus ARC2 } & EN & 1.83 & 2.03 \\
& ES & 2.10 & 1.68 \\
& S & 0.57 & -0.16 \\
& SS & 0.73 & 0.52 \\
\hline \multirow{3}{*}{ MPI-ESM versus TAMSAT } & EN & 3.74 & 3.71 \\
& ES & 1.38 & 1.31 \\
& S & 1.59 & 1.52 \\
& SS & 1.65 & 1.60 \\
\hline & EN & 0.70 & -0.37 \\
MPI-ESM versus TRMM & ES & 1.20 & 1.07 \\
& S & 1.17 & -1.07 \\
& SS & 0.93 & -0.61 \\
\hline
\end{tabular}

precipitation, especially over the $\mathrm{EN}$ and $\mathrm{S}$ region and over ES and SS in July, August, and September. In comparison with ARC2, TRMM precipitation overestimates over $S$ and SS regions. On the other hand, TAMSAT rain amount does not agree with ARC2 and GPCC rains over EN and ES regions; however, the difference between the datasets is less over S and SS regions. COSMO-CLM shows high standard deviation and the highest daily values, especially in July, August, and September over the EN and $S$ regions while MPI-ESM displays lower values. In general, observations and models overlap in most months and regions within their standard deviation. 


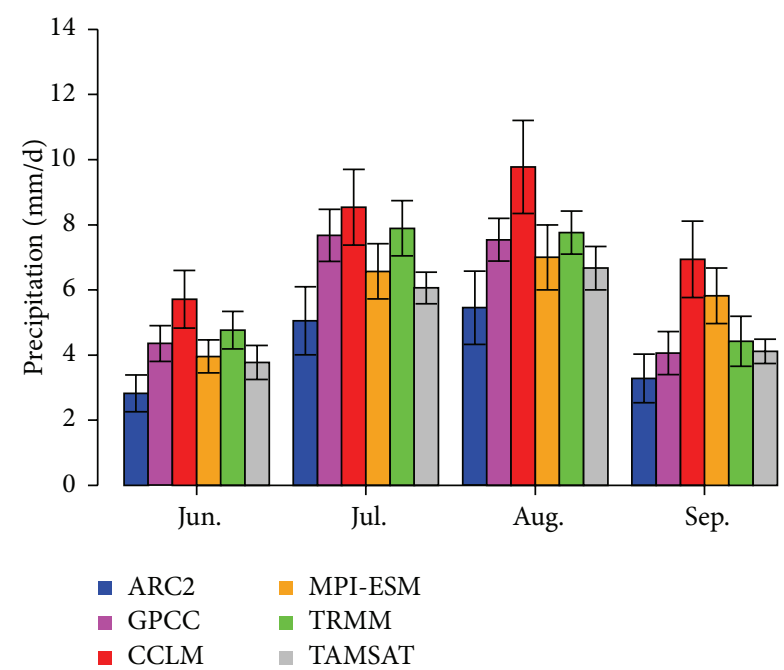

(a) EN

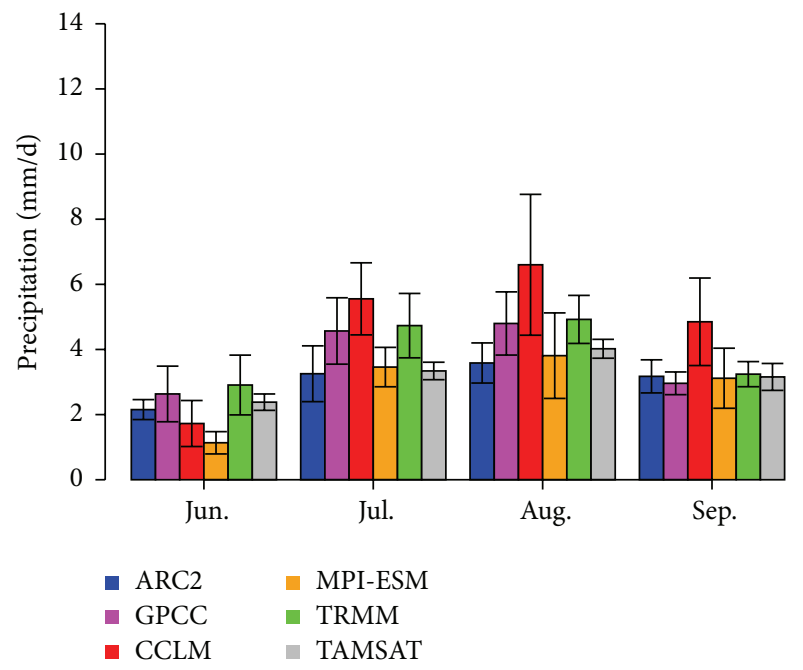

(c) $\mathrm{S}$

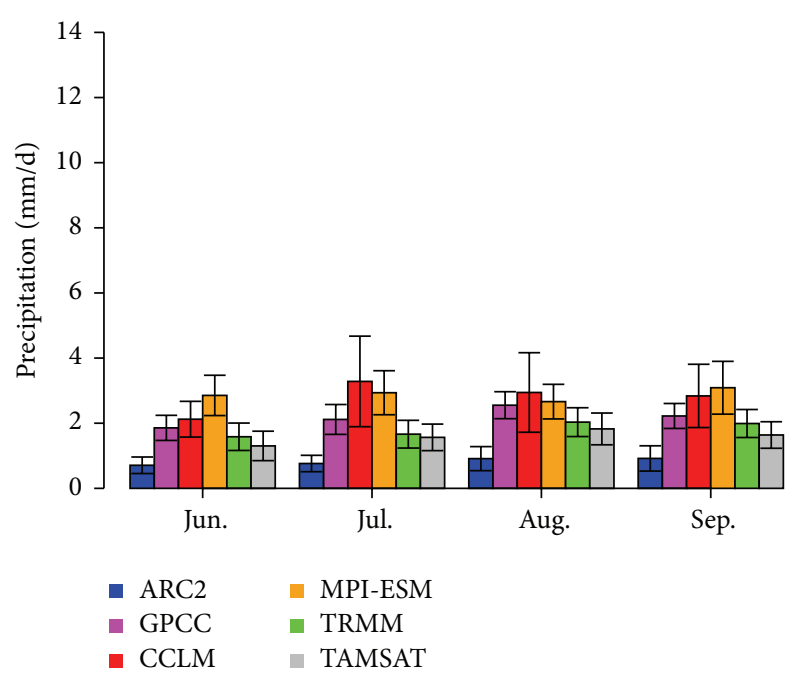

(b) ES

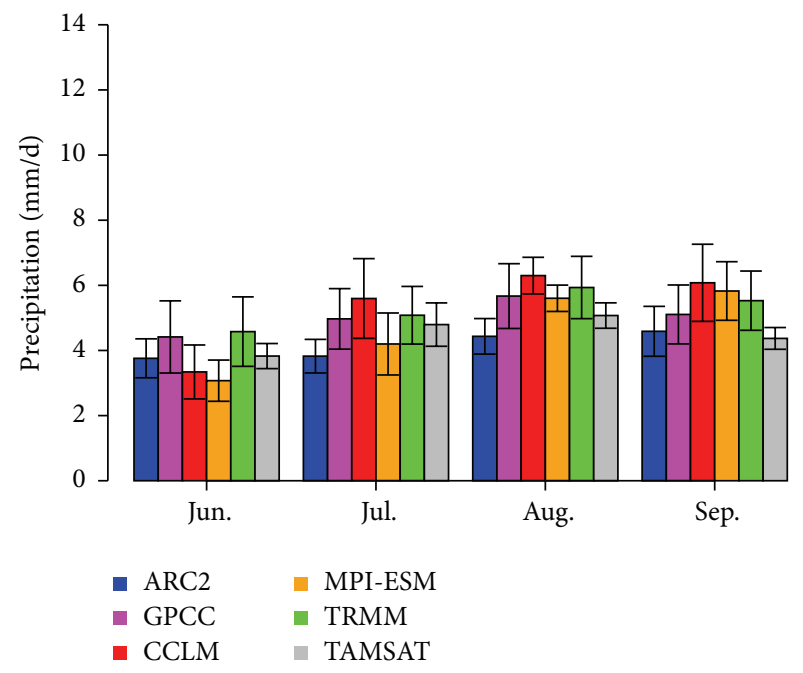

(d) SS

FIgURE 4: Daily mean precipitation $(\mathrm{mm} / \mathrm{d})$ of June to September averaged over the selected regions. Bars indicate the standard deviation.

In Figure 5 we present the interannual variability of our data. The precipitation is standardized by subtracting the climatological mean of 2000-2009 from each month and dividing it by the standard deviation of 2000-2009. The different observational datasets do not seem to agree with each other in the course of a ten-year period. ARC2 and GPCC show in 2000, 2004, and 2009 the highest differences in precipitation anomalies over the EN region. Regionally, the discrepancies between ARC2 and GPCC are lower over the ES, S, and SS regions, except over the Sudan region in 2001. TAMSAT variability is out of phase for the years 2006 and 2008. In contrast, GPCC and TRMM show consistent features for all years and regions (see also the high correlation). One reason of this diverse behaviour might be the orography of this region where interpolation algorithms are most difficult. The mountains generally act as a barrier for airflow that could challenge the satellite rainfall estimation [30]. In general, satellites experience more difficulties in detecting precipitation over land than over the ocean. The modelled anomalies of COSMO-CLM and MPI-ESM look quite similar for all regions. However, compared with gridded datasets significant difference is observed over ES, S, and SS in 2001 and 2004. The 2006 and 2007 wet years and 2002 and 2009 dry years are well captured by COSMO-CLM, especially over the EN region where June to September is the main rainy season.

The Pearson correlation of the JJAS mean precipitation is calculated for the observational and model data with GPCC as reference dataset for the mean JJAS precipitation. CCLM outperforms MPI-ESM over EN whereas for the other three regions the skill of both model forecasts is comparable. While still some signal shows up over the Sudan (S) region, for SS and especially ES, both models have huge difficulties in getting the signals right. In addition, the correlation of GPCC with the other observational datasets confirms the large discrepancies between them. 


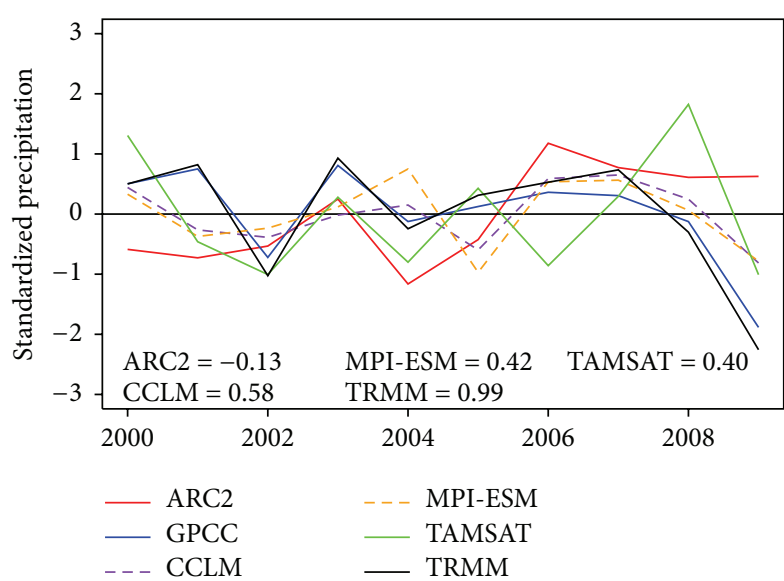

(a) EN

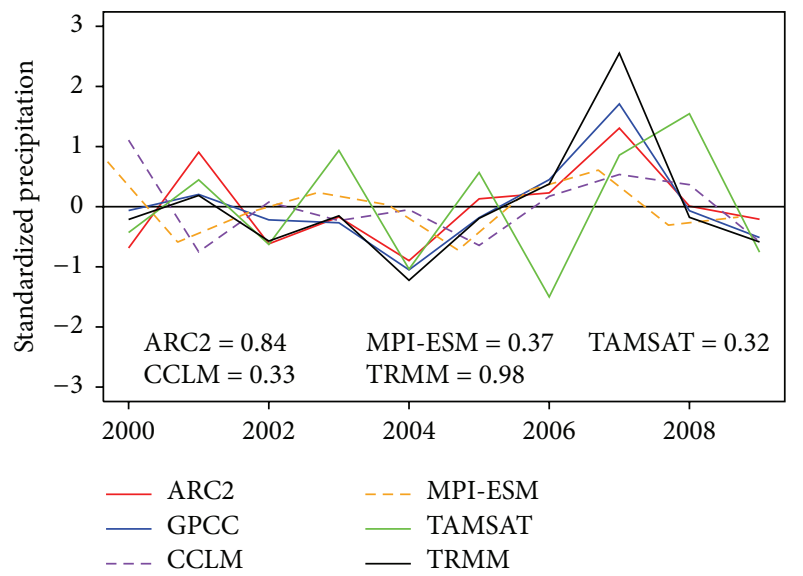

(c) $\mathrm{S}$

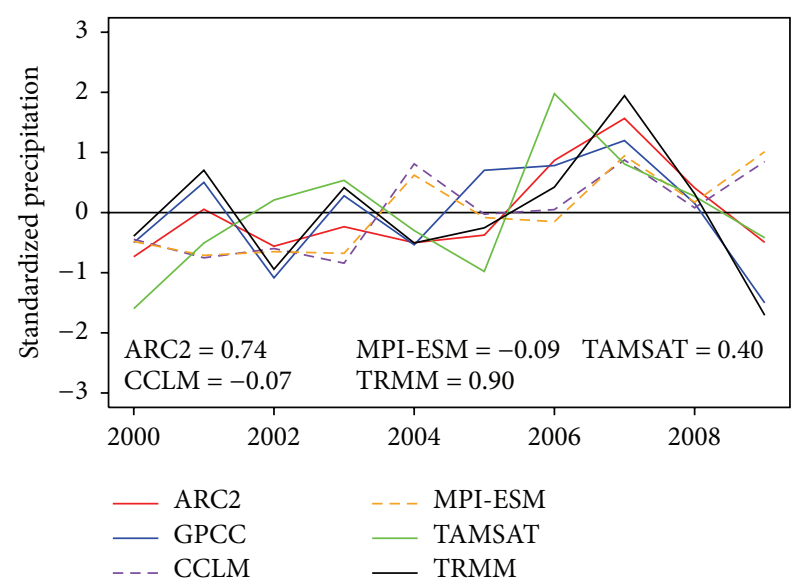

(b) ES

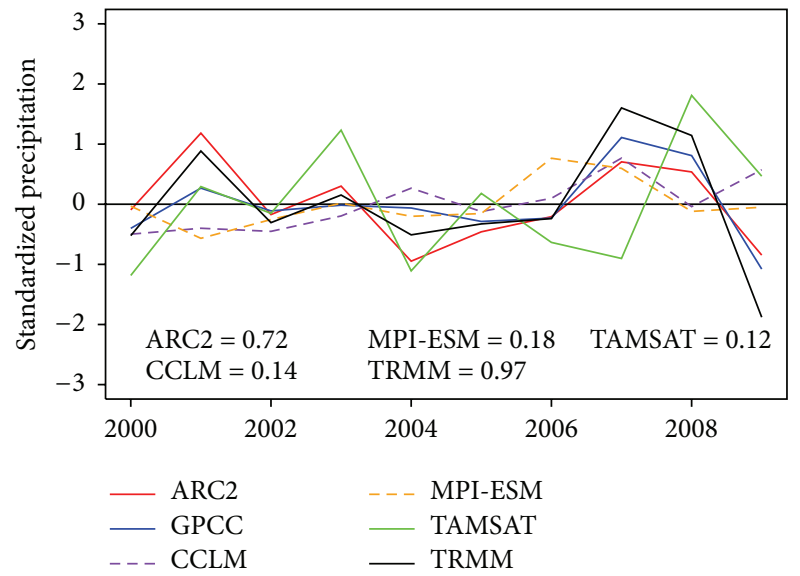

(d) SS

FIGURE 5: Interannual variability of standardized daily precipitation $(\mathrm{mm} / \mathrm{d})$ and JJAS mean. Rainfall correlations (observed and modelled with respect to GPCC) are shown inside the figure boxes.

5.4. Added Value. In this section we discuss both the real and potential added value of COSMO-CLM for East Africa. We investigate the potential added value comparing TRMM, ARC2, and COSMO-CLM precipitation products upscaled from $0.22^{\circ}$ to coarser resolution to understand the variation of extreme precipitation with horizontal resolution and the presence of small scale process over selected regions.

5.4.1. Real Added Value. In Figure 3 we found that COSMOCLM and MPI-ESM produce a wet bias over the mountainous highlands of Ethiopia and a dry bias over most of the lowlands of East Africa. In this section, the added value of COSMOCLM versus MPI-ESM precipitation with respect to the reference datasets ARC2, GPCC, TRMM, and TAMSAT is discussed for the months June to September and the JJAS average. Following (1) (Section 2), COSMO-CLM has the added value if its normalized mean square error is smaller than the normalized mean square error of MPI-ESM, so that $\mathrm{rAV}$ is greater than 0 . In contrast to the RMSE comparison above separately for COSMO-CLM and MPI-ESM, we put all data onto a common grid and investigate the spatial fields here. But, in this case, the RMSE is normalized to get the spatial index ranges from -1 (RCM no added value) to 1 (RCM perfect added value) as shown in (1).

The spatial fields of real added value of COSMO-CLM with respect to the reference precipitation datasets for each month and for the JJAS average are shown in Figure 6. From Table 2 we know that the RMSE of COSMO-CLM is higher than the RMSE of MPI-ESM for almost all regions and datasets. The best coincidence between the models is given for the southern regions with respect to GPCC and TRMM.

Taking this and the discussion of Figure 5, we discard TAMSAT in the further discussion because of their highly different behaviour to ARC2, TRMM, and GPCC. Looking at Figure 6, we find large regions with added value of COSMOCLM, especially in the southern part and for the beginning of the rainy season also in the Northern Sudan region. The Ethiopian mountains are obviously a quite difficult region for COSMO-CLM.

In general, the added value over South Ethiopia and the missing added value over the central northern mountains of Ethiopia are a consistent feature in all datasets. It would be 


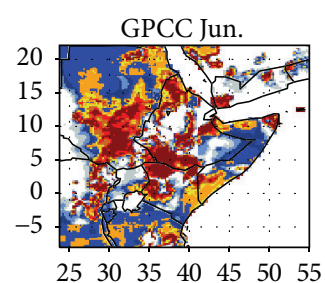

$\begin{array}{lllllll}25 & 30 & 35 & 40 & 45 & 50 & 55\end{array}$

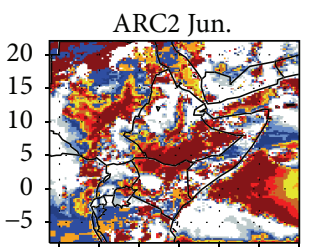

$\begin{array}{lllllll}25 & 30 & 35 & 40 & 45 & 50 & 55\end{array}$

TRMM Jun

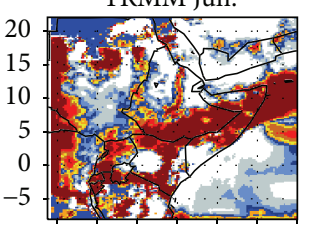

$\begin{array}{lllllll}25 & 30 & 35 & 40 & 45 & 50 & 55\end{array}$

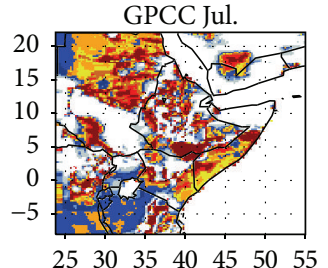

ARC2 Jul.

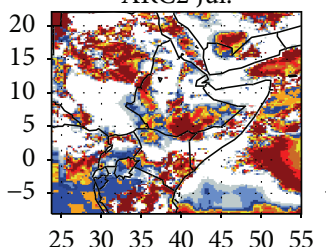

$\begin{array}{lllllll}25 & 30 & 35 & 40 & 45 & 50 & 55\end{array}$

TRMM Jul.

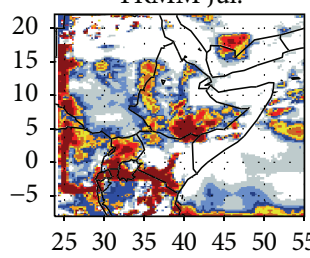

GPCC Aug.

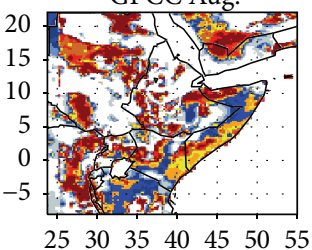

(a)

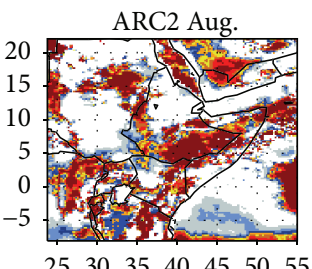

(b)

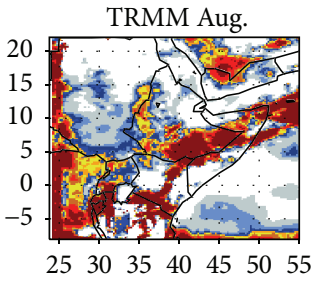

GPCC Sep.

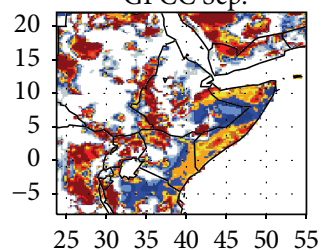

$\begin{array}{lllllll}25 & 30 & 35 & 40 & 45 & 50 & 55\end{array}$

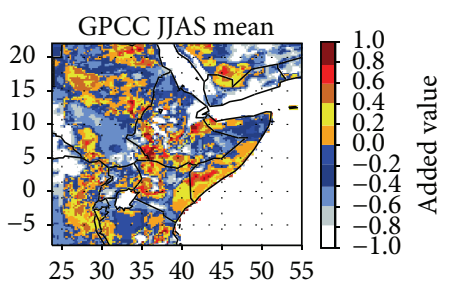

$\begin{array}{lllllll}25 & 30 & 35 & 40 & 45 & 50 & 55\end{array}$
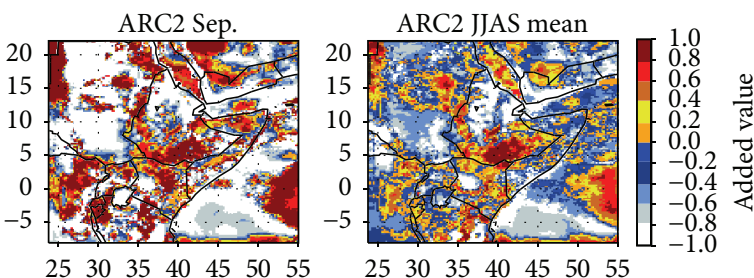

(c)
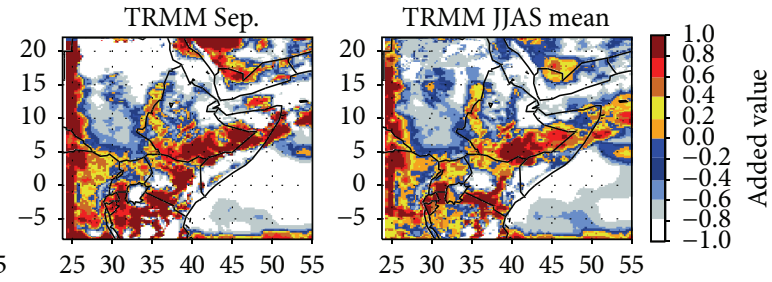

FIgURE 6: Maps of real added value of COSMO-CLM over MPI-ESM: from top to down with respect to GPCC, ARC2, and TRMM. Each of the columns represents, respectively, June, July, August, September, and JJAS average.

highly interesting if ensemble simulations of COSMO-CLM would help to give a better estimate for the precipitation over the Ethiopian mountains.

5.4.2. Potential and Relative Potential Added Value. By upscaling high resolution regional climate model output into coarser virtual resolutions comparable to GCM scales, it is possible to identify the presence of potential small scale features which are to be resolved by the regional climate model [27].

As an index of extreme precipitation, we use the 90th and 95th percentile value of daily and 16-day precipitation to evaluate the ideal added value of our RCM for the selected regions of East Africa. Based on this, we adopt the multiscale resolution methods of [27] to evaluate the potential and relative potential added value of COSMO-CLM over East Africa.

The results are summarized in Figure 7. Daily extreme precipitation has high potential added value compared to the 16-day aggregated precipitation (Figures $7(\mathrm{a})$ and $7(\mathrm{c})$ ) due to averaging out of extreme values.

Potential added value is a metric used for an indication for the existence of small scale features. However, for easy comparison and visualization of the total added value of small scale features, we normalized potential added value with respect to the high resolution precipitation 95th percentile value to get the metric, relative potential added value (rPAV). The value of rPAV ranges from 0 (no added value) to 1 (perfect added value). We find that COSMO-CLM, TRMM, and ARC2 have higher rPAV over the ES and EN region than over $\mathrm{S}$ and SS, with the difference in magnitude being higher for TRMM and ARC2 than for COSMO-CLM (Figure 7(b)). The rPAV for the 16-day aggregated extreme precipitation (Figure 7(d)) drops down strongly for all regions in the TRMM and ARC2 dataset and a little bit in the COSMOCLM model. The rPAV value of COSMO-CLM is higher than that of TRMM and ARC2 over the regions EN, S, and SS. The reason for maximum rPAV over the EN and the ES regions could be that both regions have distinct mesoscale features such as the domain that is near to the coast, large parks, and high mountains compared with the regions SS and S. The steady drop of COSMO-CLM potential added value over EN region is an indication that COSMO-CLM simulates extreme precipitation over $\mathrm{EN}$, and in its $\mathrm{rPAV}$ the value is normalized and follows the trend of other datasets. The higher value of relative potential added value of TRMM and ARC2 compared to COSMO-CLM suggests that COSMO-CLM does not completely resolve the small scale processes, even though ARC2 underestimates and TRMM overestimates total precipitation compared to other gridded precipitation datasets. Over the four regions which have distinct orographic features, a high relative potential added value is observed over EN and ES regions which are characterized by steep and sharp relief.

5.5. Frequency Distribution of Multiscale Precipitation. To investigate the variation of precipitation in frequency and in amount across aggregated spatial and temporal virtual 


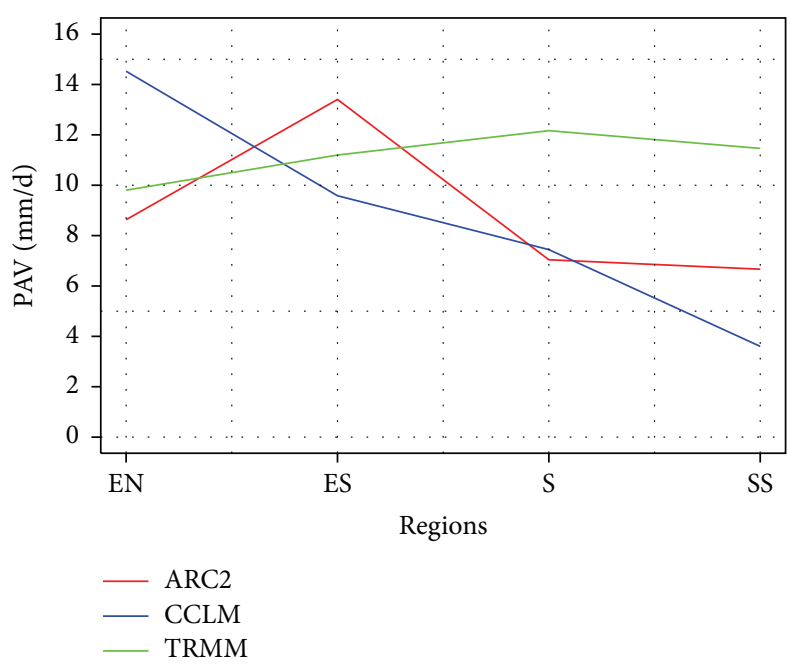

(a) Daily PAV

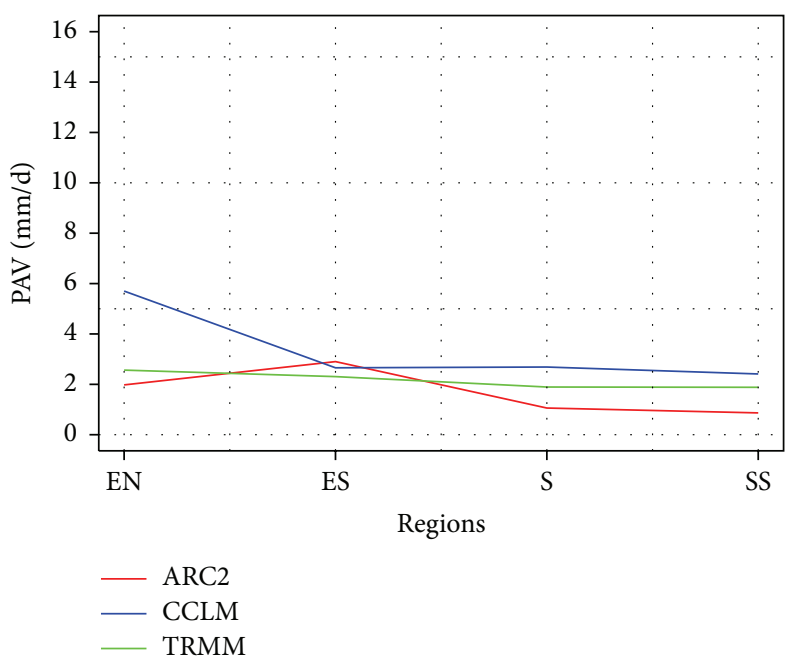

(c) 16-day PAV

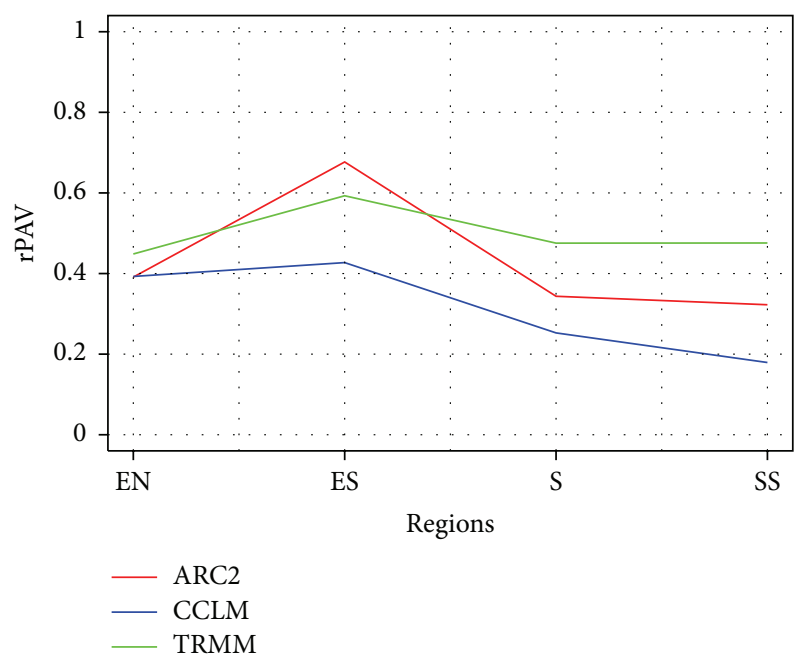

(b) Daily rPAV

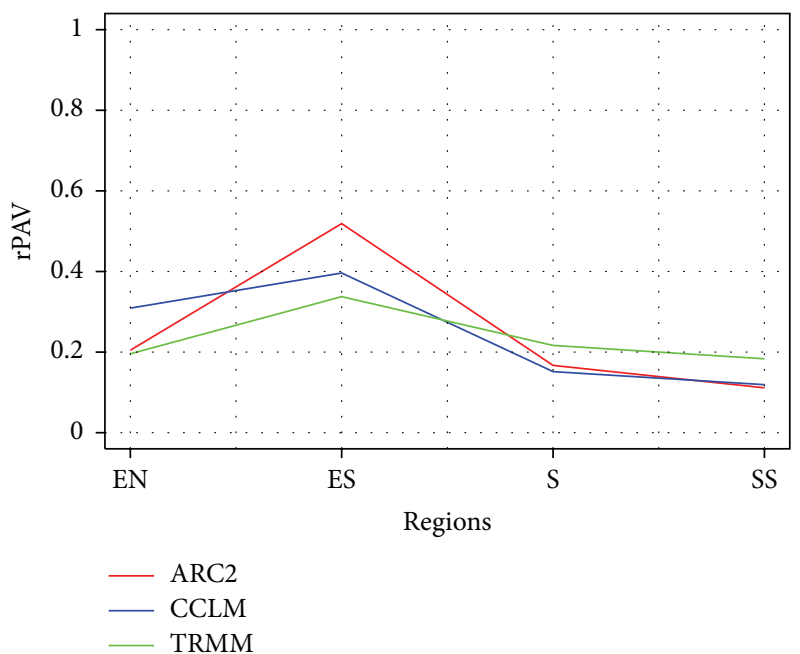

(d) 16-day rPAV

FIGURE 7: Potential (left) and relative potential (right) added value of daily (top) and 16-day aggregated (bottom) precipitation from ARC2, TRMM, and COSMO-CLM over the 4 East African regions; (a) daily PAV, (b) daily rPAV, (c) 16-day PAV, and (d) 16-day rPAV.

resolution in daily and up to 16-day sum, precipitation is aggregated from high spatial resolution $\left(0.22^{\circ}\right)$ to low virtual spatial resolution $\left(7.04^{\circ}\right)$ and from high temporal resolution (daily) to low temporal resolution (16 days). The relative frequency of precipitation in multiscale horizontal resolution is calculated for binned daily precipitation for June to September of 2000-2009 over each region (Figure 8) for COSMOCLM, TRMM, and ARC2. Comparing the virtual resolutions, we observe that $(\mathrm{i})$ the lowest precipitation $(<1 \mathrm{~mm} / \mathrm{d})$ shows the highest frequency at high resolution, (ii) low to medium precipitation $(5-10 \mathrm{~mm} / \mathrm{d}$ ) occurs predominantly at the vGCM scale, and (iii) the highest precipitation events most frequently occur in high resolution. The frequency distribution of the regional model resolution only changes considerably for very coarse resolution. The ARC2 seems to be really sensitive to a changing horizontal scale.
For the medium range of daily precipitation $(5-20 \mathrm{~mm} /$ d), it is found that highest frequencies occur at the lowest resolution scale, for example, with a maximum of $20 \mathrm{~mm} / \mathrm{d}$ at $3.52^{\circ}$ grid resolution over North Ethiopia for COSMOCLM and TRMM, with maximum value of $10 \mathrm{~mm} / \mathrm{d}$ at $3.52^{\circ}$ over North Ethiopia for ARC2 and over South Ethiopia for COSMO-CLM, ARC2, and TRMM spatially aggregated precipitation.

For heavy precipitation $(>50 \mathrm{~mm} / \mathrm{d})$, again a higher frequency is found for all regions at the highest spatial resolution, $0.22^{\circ}$. The extreme precipitation frequency of COSMO-CLM is higher than that of ARC2 over all regions.

We find similar relative frequency distributions for the regions Sudan (S) and South Sudan (SS) (not shown). Comparing frequency of precipitation at fine and coarse resolution, high frequency of extreme precipitation is captured at 

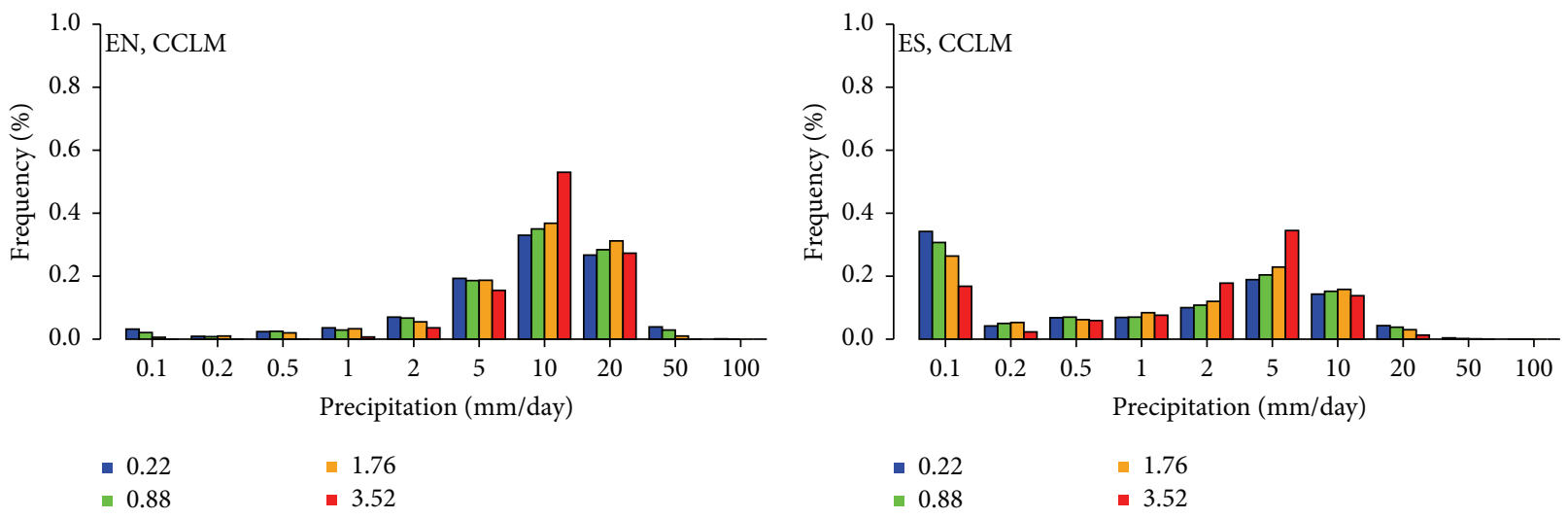

(a)
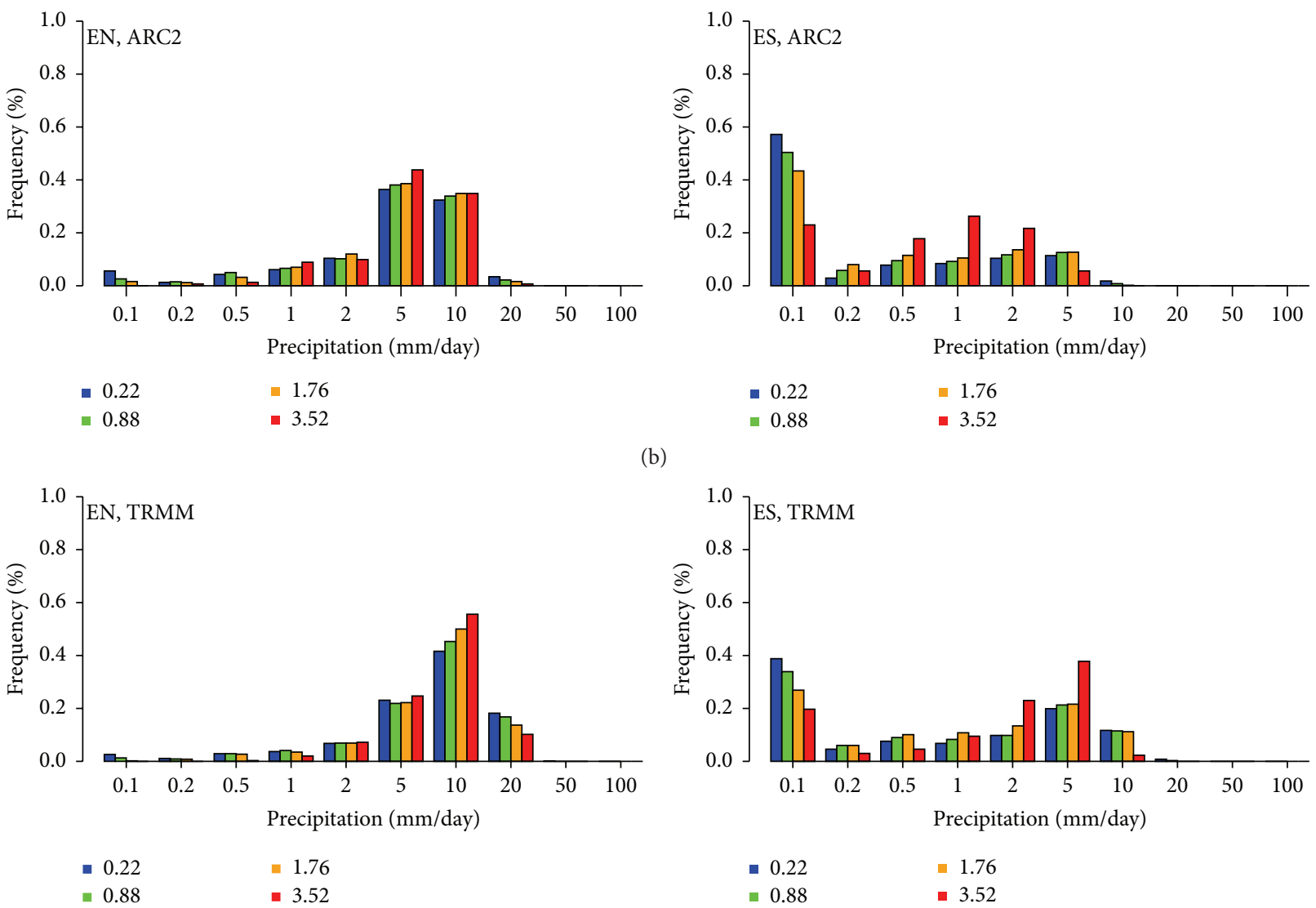

(b)

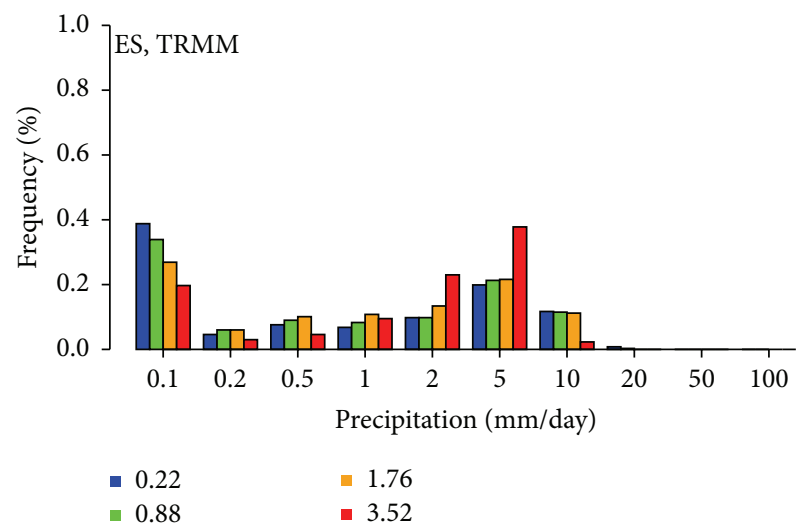

(c)

Figure 8: Frequency distribution of daily precipitation for COSMO-CLM (top), ARC2 (middle), and TRMM (bottom) over multiscale resolution for North Ethiopia (EN, left) and South Ethiopia (ES, right). Coloured bars show the different spatial resolutions.

fine resolution, while medium range precipitation frequency is captured at coarse resolution.

5.6. Multiscale Extreme Precipitation. We consider the spatial aggregated variation of 90th and 95th percentile of daily summer precipitation (June to September) to describe the extremes of the period 2000-2009 over multiscale resolutions in each region. The extreme precipitation value is reduced in coarse resolution in both daily and 16-day multiscale resolution which is in direct relation to the spatial and temporal resolutions (Figure 9). The main reason is that at high resolution small features which lead to extremes are resolved by the regional climate model. In Figure 9(b), we see that at the lowest resolution $\left(7.04^{\circ}\right)$ the 95 th percentile gap between the different regions is reduced in both daily and 16-day temporal resolutions compared with the highest resolution $\left(0.22^{\circ}\right)$. This indicates a reduced influence of small scale processes on coarser grid resolution. But this is not the case for ARC2, where the difference between the regions is approximately constant through the different resolutions, with exception of 


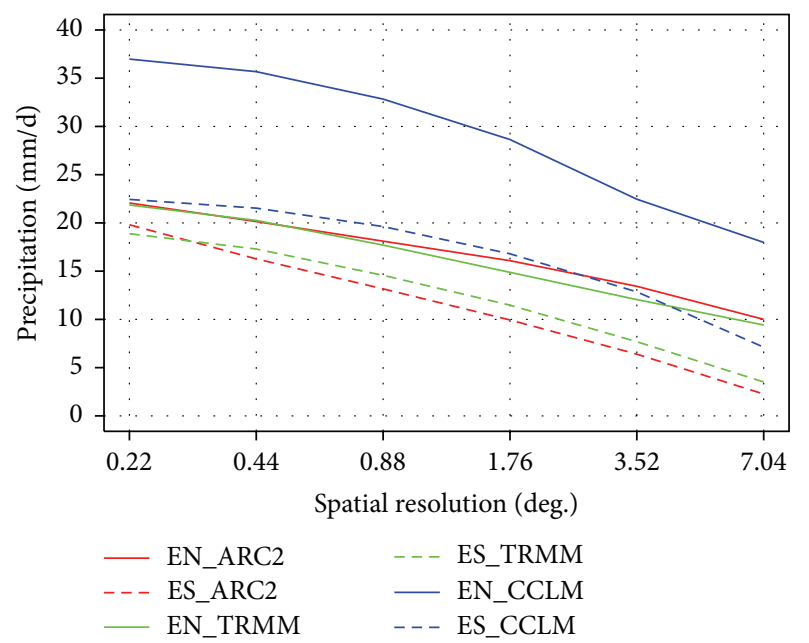

(a) $95 \%$ over ES and EN daily

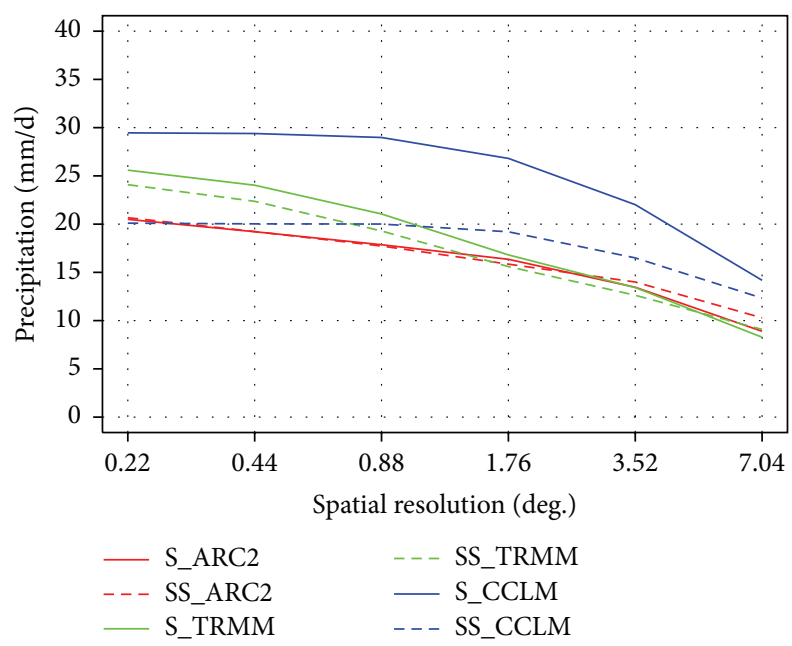

(c) $95 \%$ over S and SS daily

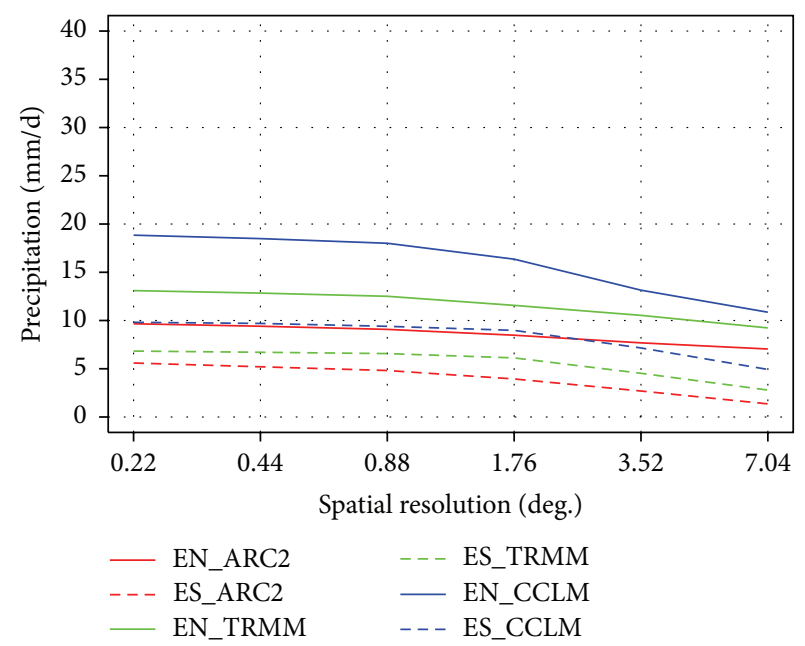

(b) $95 \%$ over EN and ES 16 days

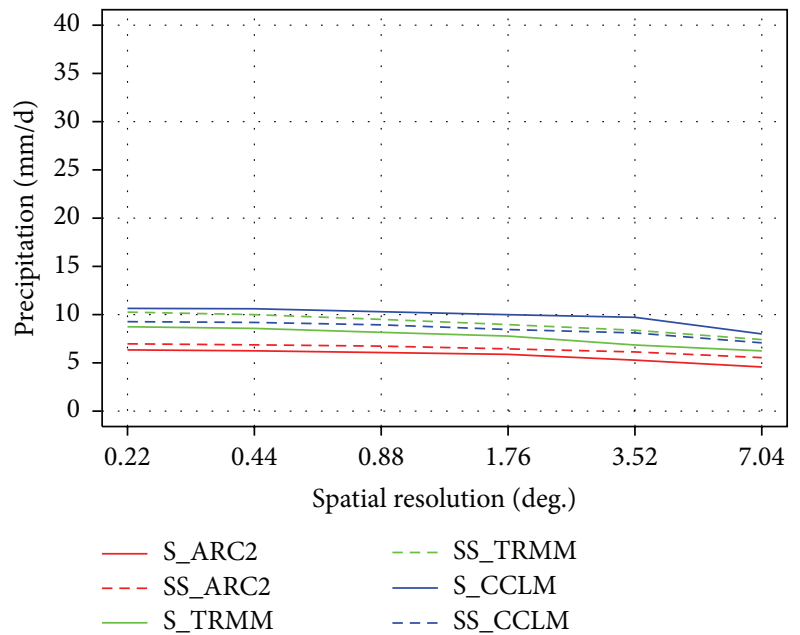

(d) $95 \%$ over $\mathrm{S}$ and $\mathrm{SS} 16$ days

FIGURE 9: 95th percentile of precipitation ( $\mathrm{mm} / \mathrm{d}$ ) for different horizontal resolutions and regions; for COSMO-CLM (blue), TRMM (green), and ARC2 (red) and (a) daily over EN and ES, (b) 16 days over EN and ES, (c) daily over S and SS, and (d) 16 days over S and SS regions.

the ES region. The results for the 90th percentile are very similar (data not shown). In general, comparing the daily extreme precipitation at fine resolution $\left(0.22^{\circ}\right)$ and at virtual coarse resolution we found that the extreme precipitation is reasonably well captured at the fine resolution.

\section{Discussion and Conclusions}

We investigated the performance of downscaled seasonal hindcasts (JJAS, 2000-2009) over East Africa by using MPIESM-LR as the driving and COSMO-CLM as the downscaling model. Precipitation was the variable of interest. The gridded reference precipitation datasets ARC2, TAMSAT, TRMM, and GPCC are used to evaluate the performance of MPI-ESM and COSMO-CLM precipitation over this region. We selected four different regions in order to distinguish between different orography and land surface conditions. Evaluation of model results over East Africa turns out to be a challenge since already observational datasets differ considerably from each other (see, e.g., Figure 2). For instance, ARC2 underestimates precipitation comparing to all other reference datasets. This is similar to the finding of [30]. The same applies to TAMSAT, but TRMM appears to overestimate precipitation. Compared with the given reference datasets, we find that COSMO-CLM overestimates the mean June to September precipitation over the Ethiopian mountainous regions. This is in line with findings from other studies. For example, in the study of dynamically downscaled seasonal hindcasts of Diro et al. [22], the RCM, RegCM3 also overestimates precipitation over the Ethiopian highlands and underestimates precipitation over the Ethiopian lowland areas. The coordinate regional domain experiment (CORDEX) Africa data used [45] and found that most of the investigated RCMs overestimate precipitation over East African regions. The overestimation of precipitation over the Ethiopian highland is due to interaction of the local and the regional climate system. 
The propagation of upper level easterly waves into Africa from Indian Ocean enhances convective development and the interaction of this convection with Ethiopian highlands activates the development of more organized convection [29]. Such strong interaction results in the grid-scale precipitation and forms intense updrafts which can produce much latent heating, too much precipitation, too low pressure, and other inappropriate feedbacks.

COSMO-CLM captures well the monthly climatological precipitation pattern as seen in Figure 5 and the interannual variability of precipitation anomalies, even though there are discrepancies between observed datasets and simulated precipitation anomalies. COSMO-CLM also captures well the dry years 2002 and 2009, and the wet years 2006 and 2007, especially over the Ethiopian highlands. Comparing the bias of MPI-ESM and COSMO-CLM precipitation with respect to reference precipitation datasets, COSMO-CLM has a wet bias with respect to all reference datasets while MPI-ESM shows a wet bias with respect to TAMSAT over all regions and over the ES region with respect to GPCC, TRMM, and ARC2 but a dry bias anywhere else. The root mean square error taken from the regional average of COSMO-CLM is smaller than the root mean square error of MPI-ESM over the SS and $S$ regions with respect to TRMM. However, over any other region the COSMO-CLM RSME is higher than the MPIESM RMSE with respect to all reference datasets. It has to be questioned though, if RMSE is the (only) appropriate score to evaluate precipitation. Because of its high discrete behaviour, precipitation generated from convective regimes like over East Africa might easily lead to a higher RMSE in a small scale model. It does not necessarily mean that a higher resolution cannot result in better forecast information. This applies as well to the discussion on the added value results, because it is based on RMSE comparison. For the real added value of COSMO-CLM using gridded datasets as reference, we found that COSMO-CLM has no added value over the Ethiopian highlands. This is quite an unexpected result because one would assume that especially over complex terrain dynamical downscaling could improve the forecast. Apart from the discussion about proper scores, the reason for this behaviour is still speculative. We assume that the overperformance of rainy events might be the "double-penalty" problem in the scales where convection and grid-scale precipitation are competitive with each other, as discussed above by Mekonnen and Rossow [29]. Over the other regions, there is quite real added value, even though there are large discrepancies in the results from one reference dataset to the other dataset. For instance, over parts of South Ethiopia COSMO-CLM adds value with reference to GPCC, TRMM, ARC2, and TAMSAT. The search of real added value of regional climate over East Africa needs further investigation using ground truth dataset as well as advanced metrics with more ensemble members' simulation.

Furthermore, the use of multiscale resolution approach to evaluate the potential added value of COSMO-CLM by aggregating in space from high spatial resolution $\left(0.22^{\circ}\right)$ to low virtual spatial resolution $\left(7.04^{\circ}\right)$ helps us to identify a region where dominant mesoscale features are present. The temporal aggregation of daily to 16-day temporal resolution indicates the relative influence of mesoscale features in regional climate model compared with daily scale, and we found that the potential influence of mesoscale on extreme precipitation, 95th percentile, is reduced in 16-day time scale (Figure 9). The frequency distribution of an amount of precipitation in multiscale resolution approach indicates that extreme precipitation is aggregated in high spatial resolution, and in 16-day temporal virtual resolution the extreme precipitation is reduced in an amount compared with daily scale (Figure 8).

The frequency of extreme precipitation value of the 95th percentiles of on day (daily) and 16 days is reduced in low temporal virtual resolution (Figure 9).

The PAV and the rPAV are important tools to identify the regions where small scale local features are dominant. The magnitude of relative potential added value is proportional to the presence of local features such as elevation, land, and water bodies of North Ethiopia (EN), South Ethiopia (ES), Sudan (S), and South Sudan (SS). However, we observe a gap in magnitude of rPAV between TRMM, ARC2, and COSMOCLM of 95th percentile precipitation indices. Compared to TRMM and ARC2, COSMO-CLM underestimates the PAV and rPAV value of the 95th percentiles, in which we speculate that COSMO-CLM that is forced by MPI-ESM does not completely resolve the dynamics of mesoscale features.

In this study, we evaluated the added value of COSMOCLM precipitation using gridded precipitation datasets. We tried to apply the findings of Di Luca et al. [27, 28] over the region of East Africa. We found indeed regions with added value but considering the whole domain the results are not always clearly indicating the benefit of a higher resolved model. This might be due to different reasons:

(i) The observational database is difficult to regard as a reliable source for model comparison because of large uncertainties among the datasets.

(ii) The application of COSMO-CLM over East Africa, especially over the mountainous regions, might need further tuning.

(iii) Di Luca et al. $[27,28]$ applied their added value approach to a completely different climatological regime than is investigated here.

(iv) The use of RMSE could limit the view of the forecast quality a regional model can provide. Next studies will take this into account.

(v) Further work will also include more ensemble members, in order to get more robust results.

Taken together, the question, whether dynamical downscaling over East Africa helps to improve seasonal forecasts, cannot finally be answered out of this study. There is still room for improvement on all aspects considered here.

\section{Competing Interests}

The authors declare that there are no competing interests regarding the publication of this paper 


\section{Acknowledgments}

This research work was done when the first author visited Deutscher Wetterdienst as an International Climate Protection fellow of Alexander von Humboldt Foundation. The first author would like to thank Alexander von Humboldt Foundation for fully funding the fellowship and Deutscher Wetterdienst for hosting this research work. In addition the authors would like to thank A. Di Luca for his valuable comments on potential added value.

\section{References}

[1] M. R. Jury, "Meteorological scenario of Ethiopian floods in 2006-2007," Theoretical and Applied Climatology, vol. 104, no. 1-2, pp. 209-219, 2011.

[2] E. Viste, D. Korecha, and A. Sorteberg, "Recent drought and precipitation tendencies in Ethiopia," Theoretical and Applied Climatology, vol. 112, no. 3-4, pp. 535-551, 2013.

[3] W. Degefu, "Some aspects of meteorological drought in Ethiopia," in Drought and Hunger in Africa: Denying Famine a Future, M. H. Glantz, Ed., pp. 23-36, Cambridge University Press, Cambridge, UK, 1987.

[4] Z. T. Segele and P. J. Lamb, "Characterization and variability of Kiremt rainy season over Ethiopia," Meteorology and Atmospheric Physics, vol. 89, no. 1-4, pp. 153-180, 2005.

[5] A. J. Challinor, J. M. Slingo, T. R. Wheeler, and F. J. DoblasReyes, "Probabilistic simulations of crop yield over western India using the DEMETER seasonal hindcast ensembles," Tellus, Series A: Dynamic Meteorology and Oceanography, vol. 57, no. 3, pp. 498-512, 2005.

[6] A. P. Morse, F. J. Doblas-Reyes, M. B. Hoshen, R. Hagedorn, and T. N. Palmer, "First steps towards the integration of a dynamic malaria model within a probabilistic multi-model forecast system," Tellus, Series A, vol. 57, pp. 464-475, 2005.

[7] M. C. Thomson, F. J. Doblas-Reyes, S. J. Mason et al., "Malaria early warnings based on seasonal climate forecasts from multimodel ensembles," Nature, vol. 439, no. 7076, pp. 576-579, 2006.

[8] T. Nakaegawa, S. Kusunoki, M. Sugi, A. Kitoh, C. Kobayashi, and K. Takano, "A study of dynamical seasonal prediction of potential water resources based on an atmospheric GCM experiment with prescribed sea-surface temperature," Hydrological Sciences Journal, vol. 52, no. 1, pp. 152-165, 2007.

[9] E. Viste and A. Sorteberg, "The effect of moisture transport variability on Ethiopian summer precipitation," International Journal of Climatology, vol. 33, no. 15, pp. 3106-3123, 2013.

[10] G. T. Diro, D. I. F. Grimes, and E. Black, "Teleconnections between Ethiopian summer rainfall and sea surface temperature: part II. Seasonal forecasting," Climate Dynamics, vol. 37, no. 1, pp. 121-131, 2011.

[11] T. K. Bahaga, G. Mengistu Tsidu, F. Kucharski, and G. T. Diro, "Potential predictability of the sea-surface temperature forced equatorial east african short rains interannual variability in the 20th century," Quarterly Journal of the Royal Meteorological Society, vol. 141, no. 686, pp. 16-26, 2015.

[12] B. Kassahun, "Weather systems over Ethiopia," in Proceedings of the First Technical Conference on Meteorological Research in Eastern and Southern, pp. 53-57, Kenya Meteorological Department, Nairobi, Kenya, 1987.

[13] T. Gissila, E. Black, D. I. F. Grimes, and J. M. Slingo, "Seasonal forecasting of the Ethiopian summer rains," International Journal of Climatology, vol. 24, no. 11, pp. 1345-1358, 2004.
[14] D. Korecha and A. G. Barnston, "Predictability of JuneSeptember rainfall in Ethiopia," Monthly Weather Review, vol. 135, no. 2, pp. 628-650, 2007.

[15] G. T. Diro, D. I. F. Grimes, and E. Black, “Teleconnections between Ethiopian summer rainfall and sea surface temperature: part I. Seasonal forecasting," Climate Dynamics, vol. 7, pp. 121-131, 2011.

[16] H. Gallée, W. Moufouma-Okia, P. Bechtold et al., "A highresolution simulation of a West African rainy season using a regional climate model," Journal of Geophysical Research D: Atmospheres, vol. 109, no. 5, Article ID D05108, 13 pages, 2004.

[17] M. A. Tadross, W. J. Gutowski, B. C. Hewitson, C. Jack, and M. New, "MM5 simulations of interannual change and the diurnal cycle of southern African regional climate," Theoretical and Applied Climatology, vol. 86, no. 1-4, pp. 63-80, 2006.

[18] H. Paeth, K. Born, R. Podzun, and D. Jacob, "Regional dynamical downscaling over West Africa: model evaluation and comparison of wet dry years," Meteorologische Zeitschrift, vol.14, no. 3, pp. 349-367, 2005.

[19] M. B. Sylla, F. Giorgi, E. Coppola, and L. Mariotti, "Uncertainties in daily rainfall over Africa: assessment of gridded observation products and evaluation of a regional climate model simulation," International Journal of Climatology, vol. 33, no. 7, pp. 1805-1817, 2013.

[20] L. M. Druyan, M. Fulakeza, and P. Lonergan, "The impact of vertical resolution on regional model simulation of the west African summer monsoon," International Journal of Climatology, vol. 28, no. 10, pp. 1293-1314, 2008.

[21] L. M. Druyan, M. Fulakeza, P. Lonergan, and E. Noble, "Regional climate model simulation of the AMMA Special Observing Period \#3 and the pre-Helene easterly wave," Meteorology and Atmospheric Physics, vol. 105, no. 3-4, pp. 191-210, 2009.

[22] G. T. Diro, A. M. Tompkins, and X. Bi, "Dynamical downscaling of ECMWF Ensemble seasonal forecasts over East Africa with RegCM3," Journal of Geophysical Research Atmospheres, vol. 117, no. 16, Article ID D16103, 2012.

[23] L. Mariotti, E. Coppola, M. B. Sylla, F. Giorgi, and C. Piani, "Regional climate model simulation of projected 21st century climate change over an all-Africa domain: comparison analysis of nested and driving model results," Journal of Geophysical Research Atmospheres, vol. 116, no. 15, Article ID D15111, 2011.

[24] H.-J. Panitz, A. Dosio, M. Büchner, D. Lüthi, and K. Keuler, "COSMO-CLM (CCLM) climate simulations over CORDEXAfrica domain: analysis of the ERA-Interim driven simulations at $0.44^{\circ}$ and $0.22^{\circ}$ resolution," Climate Dynamics, vol. 42 , no. $11-$ 12, pp. 3015-3038, 2014.

[25] L. Hernández-Díaz, R. Laprise, L. Sushama, A. Martynov, K. Winger, and B. Dugas, "Climate simulation over CORDEX Africa domain using the fifth-generation Canadian Regional Climate Model (CRCM5)," Climate Dynamics, vol. 40, no. 5-6, pp. 1415-1433, 2013.

[26] M. B. Sylla, E. L. Coppola, F. Mariotti et al., "Multi year simulation of the African climate using a regional climate model (RegCM3) with the high resolution ERA-interim reanalysis," Climate Dynamics, vol. 35, pp. 231-247, 2010.

[27] A. Di Luca, R. de Elía, and R. Laprise, "Potential for added value in precipitation simulated by high-resolution nested Regional Climate Models and observations," Climate Dynamics, vol. 38, no. 5, pp. 1229-1247, 2012. 
[28] A. Di Luca, R. de Elía, and R. Laprise, "Potential for small scale added value of RCM's downscaled climate change signal," Climate Dynamics, vol. 40, no. 3-4, pp. 601-618, 2013.

[29] A. Mekonnen and W. B. Rossow, "The interaction between deep convection and easterly waves over tropical North Africa: a weather state perspective," Journal of Climate, vol. 24, no. 16, pp. 4276-4294, 2011.

[30] M. P. Young, C. J. Williams, J. C. Chiu, R. I. Maidment, and S. Chen, "Investigation of discrepancies in satellite rainfall estimates over Ethiopia," Journal of Hydrometeorology, vol. 15, no. 6, pp. 2347-2369, 2014.

[31] B. Stevens, M. M. Giorgetta, T. Esch et al., "Atmospheric component of the MPI-M Earth System Model: ECHAM6," Journal of Advances in Modeling Earth Systems, vol. 5, no. 2, pp. 146-172, 2013.

[32] J. Baehr, K. Fröhlich, M. Botzet et al., “The prediction of surface temperature in the new seasonal prediction system based on the MPI-ESM coupled climate model," Climate Dynamics, vol. 44, no. 9-10, pp. 2723-2735, 2015.

[33] U. Böhm, M. Kucke, W. Ahrens et al., "CLM-the climate version of LM: Brief description and long-term applications," COSMO Newsletter, vol. 6, pp. 225-235, 2006.

[34] B. Rockel and B. Geyer, "The performance of the regional climate model CLM in different climate regions, based on the example of precipitation," Meteorologische Zeitschrift, vol. 17, no. 4, pp. 487-498, 2008.

[35] M. Tiedtke, "A comprehensive mass flux scheme for cumulus parameterization in large-scale models," Monthly Weather Review, vol. 117, no. 8, pp. 1779-1800, 1989.

[36] N. S. Novella and W. M. Thiaw, "African rainfall climatology version 2 for famine early warning systems," Journal of Applied Meteorology and Climatology, vol. 52, no. 3, pp. 588-606, 2013.

[37] D. I. F. Grimes, E. Pardo-Igúzquiza, and R. Bonifacio, "Optimal areal rainfall estimation using raingauges and satellite data," Journal of Hydrology, vol. 222, no. 1-4, pp. 93-108, 1999.

[38] G. J. Huffman, R. F. Adler, D. T. Bolvin et al., "The TRMM Multisatellite Precipitation Analysis (TMPA): quasi-global, multiyear, combined-sensor precipitation estimates at fine scales," Journal of Hydrometeorology, vol. 8, no. 1, pp. 38-55, 2007.

[39] U. Schneider, A. Becker, P. Finger, A. Meyer-Christoffer, M. Ziese, and B. Rudolf, "GPCC's new land surface precipitation climatology based on quality-controlled in situ data and its role in quantifying the global water cycle," Theoretical and Applied Climatology, vol. 115, no. 1-2, pp. 15-40, 2014.

[40] A. Becker, P. Finger, A. Meyer-Christoffer et al., "A description of the global land-surface precipitation data products of the Global Precipitation Climatology Centre with sample applications including centennial (trend) analysis from 1901-present," Earth System Science Data, vol. 5, no. 1, pp. 71-99, 2013.

[41] R. E. Hart and R. H. Grumm, "Using normalized climatological anomalies to rank synoptic-scale events obejectively," Monthly Weather Review, vol. 129, no. 9, pp. 2426-2442, 2001.

[42] A. Dosio, H.-J. Panitz, M. Schubert-Frisius, and D. Lüthi, "Dynamical downscaling of CMIP5 global circulation models over CORDEX-Africa with COSMO-CLM: evaluation over the present climate and analysis of the added value," Climate Dynamics, vol. 44, no. 9-10, pp. 2637-2661, 2015.

[43] F. Giorgi, "Dependence of the surface climate interannual variability on spatial scale," Geophysical Research Letters, vol. 29, no. 23, pp. 16.1-16.4, 2002.
[44] R. Laprise, L. Hernández-Díaz, K. Tete et al., “Climate projections over CORDEX Africa domain using the fifth-generation Canadian Regional Climate Model (CRCM5)," Climate Dynamics, vol. 41, no. 11-12, pp. 3219-3246, 2013.

[45] H. S. Endris, P. Omondi, S. Jain et al., "Assessment of the performance of CORDEX regional climate models in simulating East African rainfall," Journal of Climate, vol. 26, no. 21, pp. 84538475,2013 

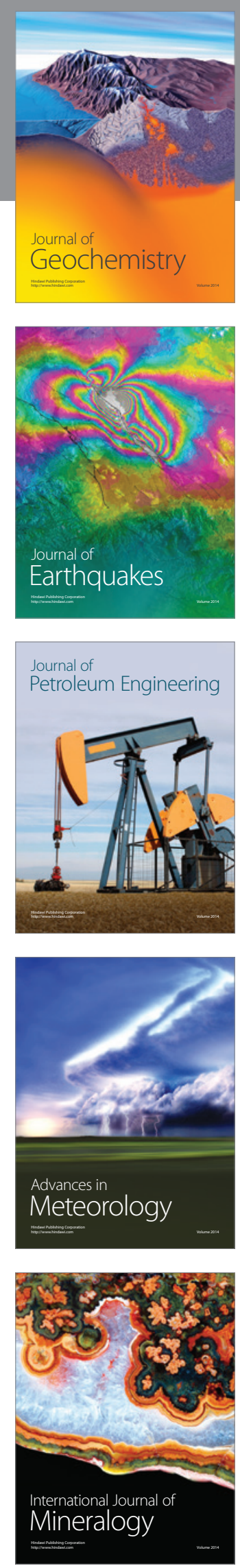
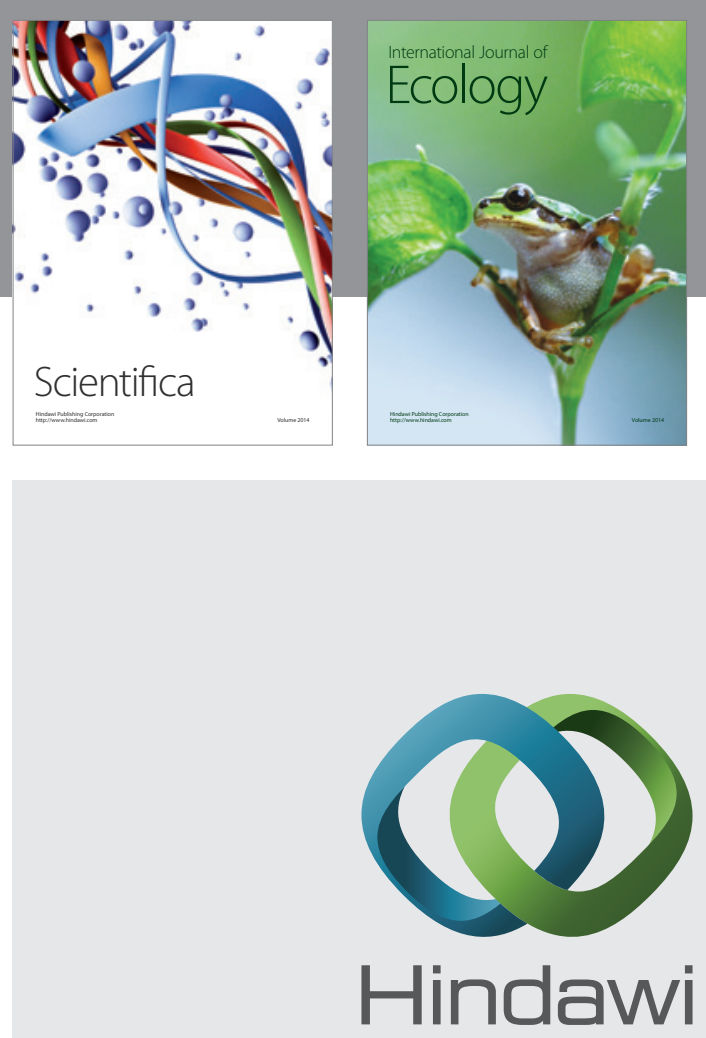

Submit your manuscripts at

http://www.hindawi.com
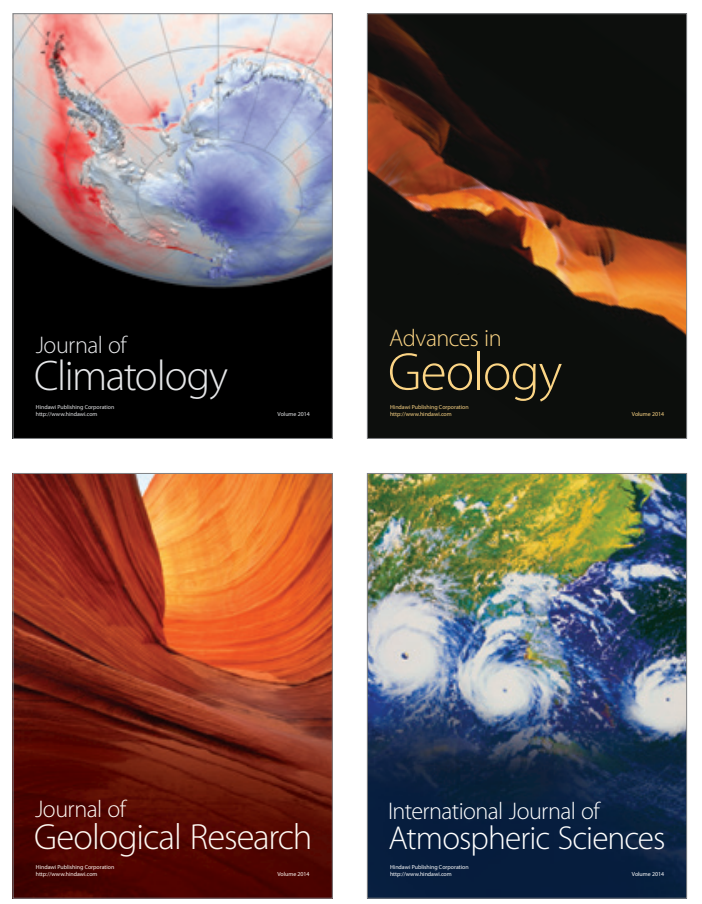

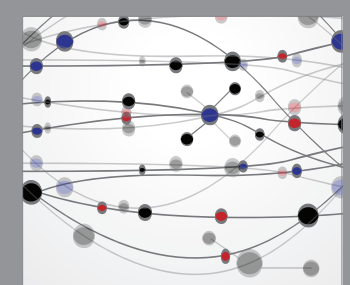

The Scientific

\section{World Journal}
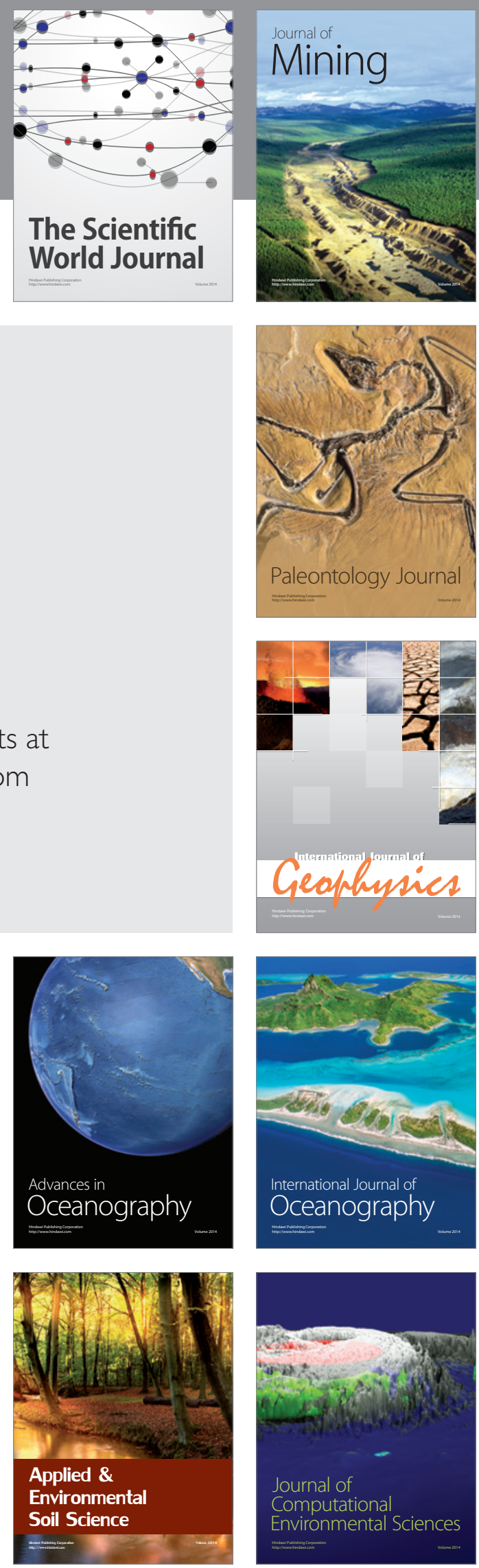